\title{
Restrições Financeiras e a Decisão de Investimento das Firmas Brasileiras
}

\author{
Guilherme Kirch*, Jairo Laser Procianoy ${ }^{\dagger}$, Paulo Renato Soares Terra ${ }^{\ddagger}$
}

\author{
Conteúdo: 1. Introdução; 2. Metodologia, Amostra, Coleta e Tratamento de Dados; 3. Análise \\ dos Resultados; 4. Considerações Finais. \\ Palavras-chave: Investimento, Restrições Financeiras, Mercados Financeiros, Métodos de Dados \\ em Painel, Brasil. \\ Códigos JEL: $\quad$ G31, G32.
}

O estudo objetiva testar a relação entre restrições ao crédito e investimento das firmas brasileiras utilizando a estratégia delineada por Almeida e Campello (2007), a qual se mostra robusta às diversas críticas levantadas pela literatura. Os resultados encontrados sugerem que: 1) firmas classificadas como não restritas, em geral, comportam-se exatamente como prevê o modelo neoclássico; e 2) firmas classificadas como restritas comportam-se de maneira consistente com o modelo de Almeida e Campello (2007). Esses resultados diferem substancialmente daqueles evidenciados em estudos anteriores no Brasil e constituem uma evidência (original) da existência do efeito multiplicador de crédito no nível de firma.

This study aims to test the relationship between financial constraints and investment for Brazilian firms using the strategy outlined by Almeida and Campello (2007), which is robust to several criticisms raised in the literature. The main results suggest that: 1) firms classified as unconstrained, in general, behave exactly like predicted by the neoclassic model; and 2) firms classified as constrained behave in a way that is consistent with Almeida and Campello (2007) model. These results differ substantially from those reported in previous studies in Brazil and constitute a novel evidence of a credit multiplier effect at the firm level.

\footnotetext{
*Universidade Federal do Rio Grande do Sul, Escola de Administração, Rua Washington Luiz 855, Sala 448, Porto Alegre, RS, 90010-460, Brasil - Tel: +55 51 3308-3836, E-mail: gkirch@ea.ufrgs.br

†Universidade Federal do Rio Grande do Sul, Escola de Administração, Rua Washington Luiz 855, Sala 325, Porto Alegre, RS, 90010-460, Brasil - Tel: +55 51 3308-3691, E-mail: jlprocianoy@ea.ufrgs.br

${ }^{\ddagger}$ Fundação Getulio Vargas, Escola de Administração de Empresas de São Paulo, Rua Itapeva, 474, $8^{\circ}$ andar, São Paulo, SP, 01332000, Brasil - Tel.: +55 11 3799-7899. E-mail: paulo.terra@fgv.br e Universidade Federal do Rio Grande do Sul, Escola de Administração, Rua Washington Luiz 855, Sala 321, Porto Alegre, RS, 90010-460, Brasil - Tel: +55 51 3308-3818, E-mail: prsterra@ea.ufrgs.br
} 


\section{INTRODUÇÃO}

Com base na hipótese de mercados de capitais perfeitos, Modigliani e Miller (1958) demonstraram que a composição dos passivos (estrutura de capital) não afeta o custo de capital da firma e, dessa forma, as decisões de investimento e financiamento são independentes. Esse resultado sugere que a demanda por investimentos das firmas é influenciada somente pelas oportunidades de investimento com valor presente líquido positivo. Como destacado por Hubbard (1998), diversos estudos empíricos a partir da metade dos anos 60 passaram a isolar as decisões reais das firmas dos fatores puramente financeiros, utilizando o resultado supramencionado como argumento.

A hipótese de mercados de capitais perfeitos, no entanto, é bastante restritiva e no mundo real, claramente, não se verifica. No mundo real existem diversas imperfeições, tais como impostos e assimetrias de informação, que tornam a hipótese de mercados de capitais perfeitos implausível (Stein, 2003). Segundo Stein (2003, p.112), "perhaps the most pervasive and important factors influencing the efficiency of corporate investment are those that arise from informational asymmetries and agency problems". A existência de assimetrias de informação entre os indivíduos pode provocar o fenômeno conhecido como racionamento de crédito: uma vez que os credores definem a taxa de juros sobre os empréstimos, um possível excesso de demanda não será corrigido por uma variação positiva no preço (aumento da taxa de juros), fazendo com que os tomadores/devedores (ou pelo menos parte destes) não consigam obter o volume de crédito desejado, [ver, por exemplo Jaffee e Russell (1976), Stiglitz e Weiss (1981)]. Além disso, problemas de assimetria informacional podem elevar os custos do financiamento externo (emissão de dívidas e ações) a ponto de serem proibitivos para determinadas firmas (Greenwald et alii, 1984, Myers e Majluf, 1984).

Em função do racionamento de crédito e/ou dos custos associados ao financiamento externo as decisões de investimento podem se mostrar sensíveis à disponibilidade interna de recursos e as firmas podem demandar liquidez como forma de aliviar os efeitos das restrições de crédito sobre os investimentos futuros. Neste contexto, portanto, o argumento utilizado para isolar as decisões reais das firmas dos fatores financeiros não é mais válido. Diante disso e, principalmente, a partir de Fazzari e Athey (1987) e Fazzari et alii (1988), ${ }^{1}$ diversos estudos sobre investimento corporativo passaram a incorporar as imperfeições dos mercados de crédito acima referidas em seus modelos.

A evidência empírica para a economia americana sugere que as restrições de crédito têm um papel importante nas decisões de investimento das firmas. Os resultados encontrados por Fazzari e Athey (1987), Fazzari et alii (1988), Gilchrist e Himmelberg (1995), entre outros, corroboram a hipótese de que a disponibilidade interna de recursos (fluxos de caixa) tem efeito positivo e estatisticamente significante sobre o investimento corporativo, principalmente para firmas classificadas como restritas financeiramente. ${ }^{2}$ Kaplan e Zingales (1997) e Cleary (1999) ${ }^{3}$ também apresentam evidências que confirmam uma relação positiva entre os fluxos de caixa e a demanda por investimento das firmas, mas seus resultados sugerem que a sensibilidade do investimento aos fluxos de caixa é maior para firmas consideradas não restritas. Cleary et alii (2007) argumentam e oferecem evidências de que os resultados de Fazzari et alii (1988) e Kaplan e Zingales (1997) não são conflitantes, mas sim facetas de uma relação em forma de U entre investimento e fundos internos. As diferenças entre estes estudos, segundo os autores, seriam frutos dos critérios de classificação utilizados: enquanto que Fazzari et alii (1988) procuram classificar as firmas quanto ao grau de assimetria informacional (determinante das condições de crédito), Kaplan e Zingales (1997) e Cleary (1999) classificam as firmas quanto a sua saúde financeira (fator fortemente relacionado com os fundos internos).

\footnotetext{
${ }^{1}$ Fazzari e Athey (1987), por exemplo, citam uma série de estudos anteriores que defendiam a visão alternativa de que o investimento poderia ser restringido pela capacidade de geração de caixa da firma. Como os autores destacam, estes estudos ficaram, por muitos anos, à sombra da teoria neoclássica de investimento.

${ }^{2}$ Fazzari e Athey (1987) não classificam as firmas a priori para fins de estimação da demanda por investimentos.

${ }^{3} \mathrm{Em}$ um contexto internacional, Cleary (2005) obtém evidências semelhantes àquelas encontradas por Cleary (1999).
} 
Uma das principais críticas aos modelos de investimento que incluem a variável fluxos de caixa entre as explicativas é a de que a mesma seria apenas uma proxy para o conjunto de oportunidades de investimento da firma não captado corretamente pelo $Q$ de Tobin. ${ }^{4}$ Como questionado por Gilchrist e Himmelberg (1995, p.542): "Do increases in cash flow relax financing contraints and increase investment by reducing the shadow cost of capital, as the above literature suggest? Or do increases in cash flow merely forecast the firm's investment opportunities?"

Com o intuito de responder estas questões e contornar os problemas relacionados aos possíveis erros de mensuração na variável oportunidades de investimento ( $Q$ de Tobin), Almeida e Campello (2007) exploram o papel da tangibilidade dos ativos na capacidade da firma de obter recursos externos e propõem uma nova estratégia de identificação. Os resultados reportados pelos autores são fortemente consistentes com a hipótese de que restrições financeiras afetam as decisões de investimento e da maneira prevista: a tangibilidade dos ativos aumenta a sensibilidade do investimento aos fluxos de caixa de firmas restritas (efeito denominado pelos autores de "multiplicador de crédito") e tal efeito não é observado entre as firmas classificadas como não restritas financeiramente. Almeida e Campello (2007) mostram ainda que seus resultados não são afetados pelos problemas que têm sido associados com o estudo de Fazzari et alii (1988), nem por possíveis erros de mensuração na variável $Q$ de Tobin. ${ }^{5}$

No Brasil as evidências empíricas também sugerem que as restrições de crédito desempenham um papel determinante nas decisões de investimento corporativo. Os estudos de Terra (2003), Esteves Filho e Ness Jr. (2005) e Aldrighi e Bisinha (2010) apresentam evidências de que a sensibilidade do investimento aos fluxos de caixa é positiva e estatisticamente significante para a totalidade das firmas analisadas, sugerindo que as firmas brasileiras, de modo geral, sofrem restrições ao crédito. Além disso, os resultados de Terra (2003) e Aldrighi e Bisinha (2010) sugerem que a sensibilidade do investimento aos fluxos de caixa é mais forte para as firmas classificadas a priori como menos restritas financeiramente, enquanto que os resultados apresentados por Esteves Filho e Ness Jr. (2005) indicam que as firmas menores, com menor dividend payout, menor liquidez, maior endividamento e de capital nacional (principalmente as estatais) apresentam maior sensibilidade do investimento aos fluxos de caixa do que suas respectivas contrapartes. Por fim, resultados reportados por Hamburger (2004) sugerem que somente as firmas menos restritas possuem sensibilidade do investimento aos fluxos de caixa positiva e estatisticamente significativa.

A principal ressalva que pode ser feita a esses estudos na realidade brasileira é o não tratamento daquela que vem sendo uma das críticas mais contundentes aos modelos de investimento que incorporam os fluxos de caixa como variável explicativa: erros de mensuração na variável oportunidades de investimento. Esta restrição coloca em dúvida a evidência de que os fluxos de caixa influenciam a demanda por investimentos das firmas brasileiras pelo fato de aumentarem a disponibilidade interna de recursos de firmas com acesso limitado ao crédito. Além disso, ainda não há na realidade brasileira evidências empíricas acerca da existência de um efeito multiplicador de crédito no nível de firma, como proposto por Almeida e Campello (2007).

Para preencher essa lacuna e evitar os problemas relacionados aos erros de mensuração na variável oportunidades de investimento, o presente estudo tem como objetivo testar a relação entre restrições

\footnotetext{
${ }^{4}$ Por meio de estimadores de método dos momentos generalizados (GMM) robustos a erros de mensuração, Erickson e Whited (2000) reportam resultados que sugerem que os fluxos de caixa não são importantes para a decisão de investimento corporativo. Gomes (2001) argumenta, com base em um modelo teórico e resultados empíricos, que a existência de restrições financeiras não é necessária nem suficiente para obter efeitos significantes dos fluxos de caixa sobre o investimento corporativo e que as correlações entre investimentos, fluxos de caixa e vendas podem ser totalmente artificiais (reflexo de choques sobre a tecnologia). Bond et alii (2004) e Cummins et alii (2006), controlando os erros de mensuração na variável $Q$ de Tobin, também obtêm evidências de que o investimento não é sensível aos fluxos de caixa gerados internamente.

${ }^{5}$ Whited (1992) e Gilchrist e Himmelberg (1995) também obtêm evidências consistentes com os modelos de investimento sob restrições financeiras por meio de estratégias que, a princípio, evitam os problemas relacionados com erros de mensuração na variável $Q$ de Tobin. No primeiro estudo a autora estima a equação de Euler derivada de um modelo de investimento e no segundo os autores constroem, por meio de estimativas de um vetor autoregressivo, o valor esperado do $Q$ de Tobin marginal.
} 
ao crédito e demanda por investimentos das firmas brasileiras utilizando a estratégia de identificação delineada por Almeida e Campello (2007), a qual se mostra robusta às diversas críticas levantadas pela literatura.

O estudo se justifica por ser realizado em uma economia em desenvolvimento e com características institucionais distintas daquelas observadas em países desenvolvidos, como os Estados Unidos, país em que foi conduzida grande parte dos estudos anteriormente mencionados. 0 mercado brasileiro, quando comparado ao norte-americano, pode ser caracterizado por:

a) Altas taxas de juros, fato que pode agravar os problemas decorrentes da assimetria informacional entre os agentes;

b) Menor proteção legal aos investidores (La Porta et alii, 1998);

c) Menor nível de desenvolvimento financeiro (Levine, 1999, Beck et alii, 2003);

d) Maior propensão dos acionistas controladores para extrair benefícios privados do controle (Leal e Saito, 2003, Dyck e Zingales, 2004).

Estes fatores, em seu conjunto, provavelmente diminuem a disposição dos investidores em prover recursos e aumentam os custos associados ao financiamento externo e as garantias exigidas para concessão de empréstimos.

No modelo proposto por Almeida e Campello (2007), quanto maior a fração recuperável dos novos investimentos, maior será o efeito de um choque exógeno na disponibilidade interna de recursos sobre a demanda por investimentos da firma restrita (efeito multiplicador de crédito). A fração recuperável, por sua vez, é uma função da tangibilidade dos novos ativos, bem como de outros fatores, tais como o ambiente legal (Almeida e Campello, 2007). Embora as firmas brasileiras e norte-americanas se assemelhem em termos da tangibilidade dos ativos, as diferenças institucionais existentes entre os países e, especialmente, os fatores anteriormente mencionados levam a crer que no Brasil a fração recuperável dos novos investimentos é menor que nos Estados Unidos. Em função disso, diferenças devem ser esperadas na intensidade com que as firmas brasileiras e norte-americanas reagem a determinados choques sobre os fluxos de caixa e a verificação dessas diferenças constitui uma oportunidade alternativa de testar a presença do efeito multiplicador de crédito no nível de firma.

Outra contribuição do presente estudo, quando comparado aos demais, refere-se à forma de classificação a priori das firmas em restritas e não restritas finaceiramente. Embora nos diversos estudos supramencionados vários critérios para classificação a priori das firmas tenham sido empregados, no presente estudo adotou-se somente o critério tamanho da firma. Dada a heterogeneidade existente entre os setores no que se refere ao "tamanho" das firmas, optou-se também por classificar as firmas em restritas e não restritas dentro de cada setor de atividade. Acredita-se que, a partir desses avanços, estar-se-á apto a obter conclusões consistentes e não ambíguas quanto à relação entre restrições ao crédito e demanda por investimentos das firmas brasileiras.

Os principais resultados alcançados sugerem que:

1) As firmas classificadas como não restritas financeiramente comportam-se, em geral, exatamente como prevê o modelo neoclássico, isto é, a demanda por investimentos é sensível somente às oportunidades de investimento da firma;

2) As firmas classificadas como restritas financeiramente comportam-se de maneira consistente com o modelo de Almeida e Campello (2007), isto é, a demanda por investimentos é sensível à disponibilidade de recursos internos (fluxos de caixa) e essa sensibilidade, além de positiva, é crescente no nível de tangibilidade dos ativos ("efeito multiplicador de crédito"). 
Esses resultados, de maneira geral, corroboram aqueles encontrados por Almeida e Campello (2007) na realidade norte-americana e diferem substancialmente daqueles apresentados por Terra (2003), Hamburger (2004), Esteves Filho e Ness Jr. (2005) e Aldrighi e Bisinha (2010) na realidade brasileira.

Para atender o objetivo proposto, o restante do estudo está estruturado da seguinte forma: na seção 2 apresentam-se os aspectos metodológicos, inclusive os procedimentos de coleta e tratamento dos dados; na seção 3 analisam-se os resultados dos testes empíricos; e na seção 4 apresentam-se algumas considerações finais acerca do estudo.

\section{METODOLOGIA, AMOSTRA, COLETA E TRATAMENTO DE DADOS}

Para testar os efeitos de restrições ao crédito e da tangibilidade dos ativos sobre o investimento corporativo, estimou-se, assim como em Almeida e Campello (2007), o seguinte modelo de demanda por investimentos:

$$
\operatorname{Inv}_{i, t}=\alpha_{i}+\beta_{1} Q_{i, t-1}+\beta_{2} F C_{i, t}+\beta_{3} \operatorname{Tang}_{i, t}+\beta_{4}\left(F C_{i, t} \times \operatorname{Tang}_{i, t}\right)+\mu_{t}+\varepsilon_{i, t}
$$

em que: $I n v_{i, t}$ é o investimento em ativos permanentes, por unidade de estoque de capital, da firma $i$ no período $t$. Essa variável foi medida pela razão entre os gastos de capital ${ }^{6}$ ao longo do período $t$ e o ativo imobilizado no período $t-1 ; Q_{i, t-1}$ representa as oportunidades de investimento da firma $i$ no início do período $t$, medidas pela razão entre o valor de mercado e o valor contábil dos ativos, sendo o primeiro dado por: ativo total + valor de mercado das ações - patrimônio líquido; $F C_{i, t}$ é o fluxo de caixa gerado pela firma $i$ ao longo do período $t$, por unidade de estoque de capital. Essa variável representa os recursos gerados internamente e disponíveis para novos investimentos, sendo medida da seguinte forma: [lucro líquido do exercício + depreciações, no período $t$ ] / ativo imobilizado no período $t-1$; Tang $_{i, t}$ representa a tangibilidade dos ativos da firma $i$ no período $t$, sendo a mesma medida da seguinte forma: disponível $+0.715 \times$ duplicatas a receber $+0.547 \times$ estoques $+0.535 \times$ ativo imobilizado] / ativo total. Esta medida de tangibilidade é a única no nível de firma utilizada por Almeida e Campello (2007). Ela é baseada na expectativa do valor de liquidação dos ativos obtida por Berger et alii (1996) para a economia norte-americana. Ao utilizar esses mesmos pesos para cada grupo do ativo na realidade brasileira, assume-se que sejam aplicáveis a essa realidade; ${ }^{7} \alpha_{i}$ é o efeito específico da firma $i ; \mu_{t}$ captura efeitos específicos de cada período, sendo representada por um conjunto de dummies de período (ano); e $\varepsilon_{i, t}$ é o termo de erro da equação de investimentos da firma $i$ no período $t$.

No modelo neoclássico ( $Q$ de Tobin marginal) a demanda por investimentos da firma seria uma função somente das suas oportunidades de investimento, representadas em (1) pela variável $Q$. No entanto, se as firmas sofrem restrições ao crédito, um incremento na disponibilidade interna de recursos (fluxos de caixa) poderia ter um efeito positivo sobre a demanda por investimentos e, como demonstrado por Almeida e Campello (2007), a tangibilidade dos ativos, ao promover um aumento na capacidade de crédito da firma, poderia ampliar esse efeito. Para medir o efeito dos fluxos de caixa e da tangibilidade sobre a demanda por investimentos, o modelo estimado incluiu as referidas variáveis, bem como uma interação entre as mesmas. Uma vez estimado o modelo, a sensibilidade do investimento aos fluxos de caixa pode ser assim calculada:

$$
\frac{\partial \operatorname{Inv}}{\partial F C}=\beta_{2}+\beta_{4} \times \operatorname{Tang}
$$

Por meio de (2) pode-se testar a principal implicação do modelo: para as firmas restritas a sensibilidade do investimento aos fluxos de caixa é positiva e crescente na tangibilidade dos ativos, isto é,

\footnotetext{
${ }^{6}$ Gastos de capital (CAPEX) = aquisições de ativo imobilizado + aumento do diferido.

${ }^{7}$ Resultados qualitativamente semelhantes são obtidos quando a variável tangibilidade é computada como a soma simples (sem ponderações) dos elementos patrimoniais supramencionados. Ver Testes de Robustez (subseção 3.3).
} 
$\beta_{2}+\beta_{4} \times$ Tang $>0$ e $\beta_{4}>0$. Para as firmas não restritas o investimento não deveria mostrar-se sensível às variações nos fluxos de caixa e, dessa forma, espera-se que para essas firmas $\beta_{2}=\beta_{4}=0$.

A sensibilidade do investimento à tangibilidade dos ativos pode ser obtida por:

$$
\frac{\partial \operatorname{Inv}}{\partial \operatorname{Tang}}=\beta_{3}+\beta_{4} \times F C
$$

Como a tangibilidade dos ativos aumenta a capacidade de crédito das firmas restritas, espera-se que para essas a sensibilidade do investimento à tangibilidade dos ativos seja positiva, isto é, $\beta_{3}+\beta_{4} \times$ $F C>0$. Para as firmas não restritas, a tangibilidade dos ativos não deveria restringir sua capacidade de financiar projetos de investimento (caso contrário tais firmas seriam restritas financeiramente) e, dessa forma, espera-se que para essas $\beta_{3}=\beta_{4}=0$. Quanto a variável oportunidades de investimento, espera-se que a mesma influencie positivamente o investimento corporativo, independente da condição financeira da firma (restrita e não restrita). Assim, a expectativa é de que $\beta_{1}>0$ para ambos os grupos de firmas.

O modelo (1) foi estimado separadamente para os grupos de firmas classificadas a priori como restritas e não restritas, por meio do estimador de efeitos fixos. Embora nos diversos estudos supramencionados vários critérios de classificação a priori das firmas tenham sido empregados, no presente estudo, assim como em Aldrighi e Bisinha (2010), adotou-se somente o critério tamanho da firma. Firmas pequenas são, provavelmente, mais jovens e, consequentemente, menos conhecidas, sendo assim mais vulneráveis às imperfeições de mercado induzidas por assimetrias de informação (Gilchrist e Himmelberg, 1995, Erickson e Whited, 2000). O uso do critério tamanho encontra respaldo no estudo de Beck et alii (2006) que, em pesquisa envolvendo mais de 10.000 firmas em 80 países, mostrou a utilidade das variáveis tamanho, ${ }^{8}$ idade e propriedade estrangeira como critérios de classificação a priori das firmas em restritas e não restritas. Além disso, o critério tamanho é também utilizado em diversos estudos relacionados ao tema no Brasil, entre eles: Terra (2003), Costa e Paz (2004), Zani e Procianoy (2005), Esteves Filho e Ness Jr. (2005), Aldrighi e Bisinha (2010), entre outros. ${ }^{9}$ A classificação a priori das firmas, segundo o critério tamanho, ocorreu de acordo com os seguintes esquemas:

- Esquema 1 (Ativo Total) - para cada ano do período amostral, ordenou-se as firmas em ordem crescente de ativo total (proxy para tamanho). As firmas nos 3 decis inferiores (superiores) foram classificadas como restritas (não restritas).

- Esquema 2 (Setor e Ativo Total) - para cada ano do período amostral e para cada setor de atividade, ordenou-se as firmas em ordem crescente de ativo total. As firmas nos 3 decis inferiores (superiores) foram classificadas como restritas (não restritas). Para que houvesse uma distinção clara entre firmas restritas e não restritas em cada setor, optou-se por excluir, em cada ano, os setores em que o número de firmas era inferior a 5.

Enquanto que o esquema 1 (Ativo Total) ${ }^{10}$ é utilizado em diversos estudos, entre eles Almeida e Campello (2007), Costa e Paz (2004) e Esteves Filho e Ness Jr. (2005), o esquema 2 (Setor e Ativo Total) trata-se de uma inovação do presente estudo. ${ }^{11}$ A variável logaritmo natural do ativo total possui médias e medianas estatisticamente diferentes entre os setores e o teste de Kruskal-Wallis rejeita a hipótese nula de que a referida variável nos diversos setores é oriunda da mesma população. ${ }^{12}$ Dada a heterogeneidade

\footnotetext{
${ }^{8}$ Beck et alii (2006) utilizaram o número de empregados e o log das receitas como proxy para tamanho.

${ }^{9}$ Costa e Paz (2004), Esteves Filho e Ness Jr. (2005) e Almeida e Campello (2007) utilizaram o valor do ativo total como proxy para tamanho, enquanto que Zani e Procianoy (2005) e Aldrighi e Bisinha (2010) utilizaram o valor das receitas. Terra (2003) não menciona o critério usado para separar as firmas em "grandes" e "pequenas".

${ }^{10} \mathrm{O}$ uso do ativo total como proxy para tamanho é comum na literatura financeira.

${ }^{11}$ Guariglia e Schiantarelli (1998), ao estudarem os incentivos para suavização da produção (demanda por estoques), também definem a situação financeira da firma comparando-a com as outras firmas na indústria.

${ }^{12}$ Estatísticas descritivas e testes não reportados, mas disponíveis mediante solicitação aos autores.
} 
existente entre os setores no que se refere à variável logaritmo natural do ativo total, proxy para tamanho, a definição do que vem a ser uma firma "pequena" ou "grande" somente fará sentido se cada firma for comparada com as demais firmas do seu setor. Portanto, acredita-se ser apropriado classificar as firmas entre restritas e não restritas, utilizando o critério tamanho, dentro de cada setor de atividade. Essa forma de classificação promove um equilíbrio no número de firmas classificadas como restritas e não restritas dentro de cada setor, evitando que todas as (ou uma grande proporção das) firmas em determinado setor sejam classificadas ou como restritas ou como não restritas. ${ }^{13}$

A amostra inicial do presente estudo inclui todas as firmas não financeiras ${ }^{14}$ brasileiras de capital aberto cujas informações contábeis e de mercado estavam disponíveis na base de dados da Economática $\mathbb{R}$ no período compreendido pelos anos 1995 e 2009. Os dados coletados junto à referida base de dados foram ajustados para inflação e referem-se aos demonstrativos consolidados. A escolha do ano inicial se deve ao fato de que 1995 é o primeiro ano após a implantação do plano Real. Dada a estrutura de defasagens, o período de análise compreendeu os anos de 1996 a 2009. Para fins de composição da amostra final, alguns critérios de seleção foram aplicados. Inicialmente, foram eliminadas da amostra as observações (firma-ano) em que:

a) o estoque de capital era inferior a $\mathrm{R} \$ 10$ milhões (em valores de 2010);

b) o crescimento das vendas ou ativos era superior a $100 \%$;

c) o valor da variável $Q$ era negativo ou superior a 10 .

Esses critérios de seleção também foram utilizados por Almeida e Campello (2007) ${ }^{15}$ com os seguintes propósitos:

a) Eliminar firmas muito pequenas, para as quais um modelo linear de investimento é provavelmente inadequado;

b) Eliminar observações em que houve grandes saltos nos fundamentos dos negócios, indicador típico de incorporações e reorganizações;

c) Minimizar o problema associado com os erros de mensuração na variável $Q$.

Além desses critérios, para tornar possível a estimação por efeitos fixos, a firma teve que apresentar em pelo menos dois anos (não necessariamente consecutivos) todas as informações necessárias para estimação do modelo de investimento. Por fim, para mitigar os efeitos decorrentes da presença de valores extremos, as seguintes variáveis foram winsorizadas: investimento (2,5\% da cauda direita) e fluxos de caixa (2,5\% de ambas as caudas).

A amostra final do estudo é composta por 2.532 observações de 342 firmas (painel não balanceado). Para se ter uma ideia da representatividade da amostra em termos do mercado de capitais brasileiro, a soma do valor de mercado das ações das 176 firmas que compõem a amostra final do estudo em 2009

\footnotetext{
${ }^{13}$ Esse seria o resultado esperado se as instituições financeiras (no agregado) diversificam suas carteiras de crédito. No entanto, se essas instituições (no agregado) se especializam em determinados setores, poderia-se observar setores em que quase todas as firmas são restritas ou não restritas.

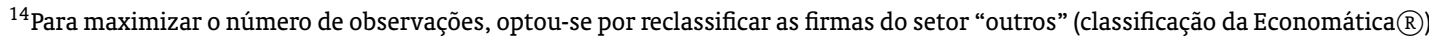
utilizando o setor NAICS (North American Industry Classification System). Essa reclassificação resultou na criação de 5 novos setores: Couro, Fumo, Produtos de Madeira, Produtos de Borracha e Produtos de Plástico. As demais firmas do setor "outros", que não puderam ser reclassificadas, foram excluídas da amostra final.

${ }^{15} \mathrm{O}$ ponto de corte adotado por esses autores no item (a) é de US\$ 5 milhões (em valores de 1985).
} 
é de R\$ 1,44 trilhão, o que representa aproximadamente $82 \%$ do valor de mercado das ações das firmas que compuseram o Ibovespa (Índice da Bolsa de Valores de São Paulo) em dezembro de 2009. ${ }^{16}$

A distribuição das observações entre restritas e não restritas, de acordo com os dois esquemas anteriormente mencionados, é apresentada por setor de atividade na Tabela 1. Das 2.532 observações, 1.534 (1.506) foram classificadas como restritas ou não restritas pelo esquema 1 (2), sendo as demais 998 (1.026) observações descartadas para fins de análise. Entre os setores, Siderurgia \& Metalurgia e Energia Elétrica são os que mais possuem observações. Como esperado, na classificação por Ativo Total (esquema 1) diversos setores possuem todas as (ou grande parte das) firmas classificadas ou como restritas ou como não restritas financeiramente. O mesmo não ocorre com a classificação por Setor e Ativo Total (esquema 2). O ônus da adoção desse esquema é a exclusão, em função dos critérios utilizados para classificação, dos seguintes setores: Agro e Pesca, Couro, Fumo, Mineração, Produtos de Borracha, Produtos de Plástico e Software e Dados.

Tabela 1: Distribuições das observações por setor

\begin{tabular}{|c|c|c|c|c|}
\hline \multirow{2}{*}{$\begin{array}{l}\text { Classificação } \longrightarrow \\
\text { Sub-Amostra } \longrightarrow\end{array}$} & \multicolumn{2}{|c|}{ Ativo Total } & \multicolumn{2}{|c|}{ Setor e Ativo Total } \\
\hline & Não Restritas & Restritas & Não Restritas & Restritas \\
\hline Agro e Pesca & - & 22 & - & - \\
\hline Alimentos e Bebidas & 57 & 84 & 67 & 67 \\
\hline Comércio & 21 & 49 & 41 & 41 \\
\hline Construção & 6 & 34 & 26 & 26 \\
\hline Couro & - & 10 & - & - \\
\hline Eletroeletrônicos & 13 & 32 & 27 & 27 \\
\hline Energia Elétrica & 218 & 6 & 106 & 106 \\
\hline Fumo & 13 & - & - & - \\
\hline Minerais não Metálicos & 1 & 23 & 3 & 3 \\
\hline Mineração & 27 & - & - & - \\
\hline Máquinas Industriais & 7 & 17 & 12 & 12 \\
\hline Papel e Celulose & 62 & 8 & 32 & 32 \\
\hline Petróleo e Gás & 44 & 7 & 27 & 27 \\
\hline Produtos de Madeira & 3 & - & - & - \\
\hline Produtos de Plástico & - & 13 & - & - \\
\hline Química & 34 & 21 & 67 & 67 \\
\hline Siderurgia \& Metalurgia & 96 & 148 & 106 & 106 \\
\hline Software e Dados & - & 1 & - & - \\
\hline Telecomunicações & 119 & 2 & 63 & 63 \\
\hline Têxtil & 4 & 159 & 85 & 85 \\
\hline Transporte Serviços & 29 & 17 & 18 & 18 \\
\hline Veículos e Peças & 13 & 114 & 73 & 73 \\
\hline Total & 767 & 767 & 753 & 753 \\
\hline
\end{tabular}

Notas: Esta tabela apresenta o número de observações (firma-ano) por setor e sub-amostra (Não Restritas e Restritas) de acordo com os dois esquemas de classificação a priori (Ativo Total e Setor e Ativo Total). As observações referem-se ao período compreendido pelos anos de 1996 e 2009.

\footnotetext{
${ }^{16} \mathrm{O}$ valor de mercado das firmas que compuseram o Ibovespa em 2009 foi obtido do site da BM\&FBovespa: http://www.bmfbovespa.com.br.
} 


\section{ANÁLISE DOS RESULTADOS}

Este seção é dividida em três partes. Inicialmente, são analisadas as estatísticas descritivas de variáveis de interesse. Em seguida, discutem-se os principais resultados das estimações do modelo (1). Por fim, são analisados os testes de robustez utilizados para determinar se os resultados originalmente encontrados são sensíveis ao modelo de investimento adotado, aos critérios de seleção empregados, à análise de sub-períodos e à forma de mensuração da varíavel tangibilidade.

\subsection{Estatísticas Descritivas}

Antes de analisar os resultados das estimações, é oportuno fazer uma análise das variáveis incluídas nos modelos estimados e verificar a eficácia dos critérios de classificação por meio da análise de variáveis no nível de firma relacionadas com a capacidade de obtenção de crédito e de variáveis cujos valores refletem, em linhas gerais, o comportamento de firmas restritas ou não restritas financeiramente.

Na Tabela 2 são apresentadas algumas estatísticas descritivas das variáveis incluídas no modelo estimado. Como se pode observar, em ambos os critérios de classificação, as firmas classificadas como não restritas, em média (mediana) e relativamente ao estoque de capital, investem mais e geram maiores fluxos de caixa do que as firmas classificadas como restritas, sendo as diferenças entre médias (medianas) estatisticamente significantes ao nível de 1\%. Esse fato corrobora a implicação teórica de que, ceteris paribus, firmas não restritas financeiramente investem relativamente mais que as firmas restritas. Pode-se observar também que as firmas classificadas como não restritas possuem, em média (mediana), maior tangibilidade dos ativos quando comparadas às firmas classificadas como restritas, sendo a diferença entre médias (medianas) estatisticamente significante ao nível de $1 \%$ sob a classificação Setor e Ativo Total e a diferença entre médias estatisticamente significante ao nível de $5 \%$ sob a classificação Ativo Total. Por fim, as firmas classificadas como não restritas apresentam, em média (mediana), menores (maiores) oportunidades de investimento ( $Q$ de Tobin) quando comparadas às firmas classificadas como restritas, sendo a diferença entre médias estatisticamente significante ao nível de $1 \%$ sob a classificação Setor e Ativo Total e as diferenças entre medianas estatisticamente significantes aos níveis de $1 \%$ (classificação Ativo Total) e 5\% (classificação Setor e Ativo Total).

É importante lembrar que o critério tamanho foi utilizado para classificação a priori das firmas e que, portanto, algumas diferenças observadas podem ser resultado de diferenças no tamanho das firmas. Por exemplo: é razoável supor que firmas pequenas possuam maiores oportunidades de crescimento as quais, mesmo sob a existência de restrições financeiras, são incorporadas no valor de mercado dessas companhias. Esse argumento poderia ser usado para explicar porque as firmas classificadas como restritas possuem, em média, maiores oportunidades de investimento ( $Q$ de Tobin) vis-à-vis firmas não restritas. Assim, é preciso ter em mente que somente a teoria poderá determinar se as diferenças encontradas são resultado de diferenças na situação financeira ou no tamanho das firmas (ou ambas).

Para fins de verificação da eficácia dos critérios de classificação utilizados para separar as firmas em restritas e não restritas financeiramente, são apresentadas na Tabela 3 algumas estatísticas descritivas de variáveis relacionadas com a capacidade de obtenção de crédito e de variáveis cujos valores refletem, em linhas gerais, o comportamento esperado de firmas restritas ou não restritas. Maiores valores relativos ao crescimento das vendas, rentabilidade sobre os ativos (ROA), caixa (disponibilidades) e tangibilidade podem sinalizar uma maior capacidade de pagamento das dívidas e, consequentemente, de acesso ao crédito. Consistente com essa visão, firmas classificadas como não restritas apresentam, em média (mediana) e em ambos os critérios de classificação, maior crescimento das vendas, maior rentabilidade sobre os ativos, maior nível de caixa e maior tangibilidade (com relação a esta última ver Tabela 2) quando comparadas às firmas classificadas como restritas, sendo as diferenças entre médias (medianas) estatisticamente significantes ao nível de $1 \%$.

No que se refere ao comportamento, espera-se que as firmas não restritas tenham maior endividamento de longo prazo e em moeda estrangeira, dado o maior acesso a esses mercados, e que paguem 
dividendos com maior frequência vis-a-vis firmas restritas financeiramente. Corroborando com essa expectativa, firmas classificadas como não restritas, em média (mediana) e em ambos os critérios de classificação, possuem maior endividamento de longo prazo e em moeda estrangeira e pagam dividendos com maior frequência quando comparadas às firmas classificadas como restritas, sendo as diferenças entre médias (medianas) estatisticamente significantes ao nível de 1\%. Dadas as expectativas teóricas, acredita-se que as diferenças encontradas sejam decorrentes de diferenças na real situação financeira das firmas (e não apenas função do tamanho das mesmas) e que, portanto, os critérios de classificação a priori adotados sejam apropriados.

Tabela 2: Estatísticas descritivas das variáveis incluídas no modelo (1)

\begin{tabular}{|c|c|c|c|c|c|c|c|c|c|}
\hline \multicolumn{2}{|c|}{ Classificação $\longrightarrow$} & \multicolumn{4}{|c|}{ Ativo Total } & \multicolumn{4}{|c|}{ Setor e Ativo Total } \\
\hline Estatística & Sub-Amostra & Inv & $\mathrm{Q}(\mathrm{t}-1)$ & FC & Tang & Inv & $\mathrm{Q}(\mathrm{t}-1)$ & FC & Tang \\
\hline \multirow{5}{*}{ Média } & Não Restritas & 0,225 & 1,186 & 0,242 & 0,458 & 0,238 & 1,156 & 0,280 & 0,469 \\
\hline & Restritas & 0,164 & 1,240 & 0,090 & 0,447 & 0,178 & 1,301 & 0,097 & 0,441 \\
\hline & Diferença & 0,061 & $-0,055$ & 0,152 & 0,011 & 0,060 & $-0,145$ & 0,183 & 0,029 \\
\hline & Teste $t$ & $6,17^{* * *}$ & $-1,25$ & $6,95^{* * *}$ & $1,79^{* *}$ & $5,64^{* * *}$ & $-3,30^{* * *}$ & $8,24^{* * *}$ & $4,55^{* * *}$ \\
\hline & Total & 0,195 & 1,213 & 0,166 & 0,452 & 0,208 & 1,228 & 0,188 & 0,455 \\
\hline \multirow{3}{*}{ Desvio-Padrão } & Não Restritas & 0,207 & 0,576 & 0,314 & 0,092 & 0,224 & 0,518 & 0,363 & 0,107 \\
\hline & Restritas & 0,180 & 1,064 & 0,518 & 0,137 & 0,190 & 1,094 & 0,491 & 0,136 \\
\hline & Total & 0,196 & 0,855 & 0,435 & 0,117 & 0,210 & 0,859 & 0,441 & 0,123 \\
\hline \multirow{3}{*}{$1^{\circ}$ Percentil } & Não Restritas & 0,009 & 0,477 & $-0,491$ & 0,240 & 0,009 & 0,477 & $-0,524$ & 0,085 \\
\hline & Restritas & 0,000 & 0,282 & $-0,967$ & 0,054 & 0,000 & 0,280 & $-0,967$ & 0,037 \\
\hline & Total & 0,000 & 0,337 & $-0,967$ & 0,087 & 0,000 & 0,369 & $-0,967$ & 0,048 \\
\hline \multirow{3}{*}{$1^{\circ}$ Quartil } & Não Restritas & 0,094 & 0,878 & 0,078 & 0,400 & 0,096 & 0,857 & 0,088 & 0,411 \\
\hline & Restritas & 0,040 & 0,700 & $-0,149$ & 0,385 & 0,049 & 0,741 & $-0,071$ & 0,382 \\
\hline & Total & 0,069 & 0,792 & 0,014 & 0,393 & 0,071 & 0,800 & 0,030 & 0,397 \\
\hline \multirow{4}{*}{ Mediana } & Não Restritas & 0,175 & 1,036 & 0,189 & 0,469 & 0,179 & 1,036 & 0,208 & 0,482 \\
\hline & Restritas & 0,113 & 0,929 & 0,104 & 0,468 & 0,122 & 0,972 & 0,119 & 0,462 \\
\hline & Teste Wilcoxon & $8,81^{* * *}$ & $5,40^{* * *}$ & $7,14^{* * *}$ & $-0,11$ & $7,73^{* * *}$ & $2,34^{* *}$ & $8,30^{* * *}$ & $3,48^{* * *}$ \\
\hline & Total & 0,148 & 0,989 & 0,156 & 0,468 & 0,152 & 1,007 & 0,171 & 0,473 \\
\hline \multirow{3}{*}{$3^{\circ}$ Quartil } & Não Restritas & 0,285 & 1,325 & 0,310 & 0,514 & 0,292 & 1,309 & 0,363 & 0,532 \\
\hline & Restritas & 0,227 & 1,330 & 0,356 & 0,529 & 0,241 & 1,410 & 0,320 & 0,526 \\
\hline & Total & 0,252 & 1,325 & 0,321 & 0,520 & 0,269 & 1,347 & 0,342 & 0,530 \\
\hline \multirow{3}{*}{$99^{\circ}$ Percentil } & Não Restritas & 0,945 & 3,640 & 1,569 & 0,675 & 0,945 & 3,250 & 1,569 & 0,700 \\
\hline & Restritas & 0,945 & 6,114 & 1,569 & 0,740 & 0,945 & 6,114 & 1,569 & 0,709 \\
\hline & Total & 0,945 & 5,068 & 1,569 & 0,705 & 0,945 & 4,951 & 1,569 & 0,708 \\
\hline
\end{tabular}

Notas: Esta tabela apresenta estatísticas descritivas das variáveis incluídas no modelo (1) por sub-amostra (Não Restritas, Restritas e Total) de acordo com os dois esquemas de classificação a priori (Ativo Total e Setor e Ativo Total). A sub-amostra Total compreende as firmas classificadas como não restritas ou restritas. Observações do período compreendido pelos anos de 1996 e 2009 são usadas para computar as estatísticas descritivas. No caso da média reporta-se também a diferença entre as médias dos dois grupos (Não Restritas e Restritas) e o Teste t de igualdade de médias (paramétrico) associado. No caso da mediana reporta-se também o Teste de soma de postos de Wilcoxon de igualdade de distribuições (ou medianas) (não paramétrico). Inv é o investimento em ativos fixos por unidade de estoque de capital; Q(t-1) é o Q de Tobin defasado em um período (ano); FC é o fluxo de caixa por unidade de estoque de capital; e Tang é a tangibilidade dos ativos. Para detalhes sobre a operacionalização dessas variáveis ver seção $2 .{ }^{* * *} \mathrm{e}^{* *}$ denotam significância estatística aos níveis de 1 e 5\%, respectivamente. 
Tabela 3: Estatísticas descritivas de variáveis relacionadas à capacidade de crédito e ao comportamento de firmas restritas ou não restritas

\begin{tabular}{|c|c|c|c|c|c|c|c|c|}
\hline \multicolumn{9}{|c|}{ Painel A: Classificação Ativo Total } \\
\hline \multirow{3}{*}{ Estatística } & & $\triangle \%$ & & & Dívida & Dívida & Dívida & Pgto. \\
\hline & Sub-Amostra & Vendas & ROA & Caixa & Curto & Longo & Moeda & Dividendos \\
\hline & & & & & Prazo & Prazo & Est. & (dummy) \\
\hline \multirow{5}{*}{ Média } & Não Restritas & 0,095 & 0,088 & 0,093 & 0,106 & 0,208 & 0,182 & 0,828 \\
\hline & Restritas & $-0,020$ & 0,035 & 0,061 & 0,148 & 0,103 & 0,063 & 0,460 \\
\hline & Diferença & 0,115 & 0,053 & 0,032 & $-0,042$ & 0,105 & 0,119 & 0,368 \\
\hline & Teste $t$ & $10,45^{* * *}$ & $10,50^{* * *}$ & $6,86^{* * *}$ & $-7,30^{* * *}$ & $16,47^{* * *}$ & $16,96^{* * *}$ & $15,00^{* * *}$ \\
\hline & Total & 0,038 & 0,062 & 0,077 & 0,127 & 0,155 & 0,125 & 0,644 \\
\hline \multirow{4}{*}{ Mediana } & Não Restritas & 0,064 & 0,081 & 0,065 & 0,084 & 0,204 & 0,162 & 1,000 \\
\hline & Restritas & $-0,002$ & 0,041 & 0,021 & 0,111 & 0,049 & 0,007 & 0,000 \\
\hline & Teste Wilcoxon & $10,1^{* * *}$ & $9,7^{* * *}$ & $11,1^{* * *}$ & $-3,9^{* * *}$ & $17,7^{* * *}$ & $17,8^{* * *}$ & $224,9^{* * *}$ \\
\hline & Total & 0,031 & 0,067 & 0,038 & 0,094 & 0,136 & 0,073 & 1,000 \\
\hline \multirow{3}{*}{ Desvio-Padrão } & Não Restritas & 0,193 & 0,072 & 0,092 & 0,083 & 0,118 & 0,138 & 0,378 \\
\hline & Restritas & 0,234 & 0,121 & 0,091 & 0,138 & 0,132 & 0,105 & 0,499 \\
\hline & Total & 0,222 & 0,103 & 0,093 & 0,116 & 0,136 & 0,137 & 0,479 \\
\hline \multirow[t]{2}{*}{ \# Obs } & Não Restritas & 766 & 767 & 767 & 767 & 767 & 633 & 761 \\
\hline & Restritas & 759 & 767 & 767 & 767 & 767 & 583 & 765 \\
\hline \multicolumn{9}{|c|}{ Painel B: Classificação Setor e Ativo Total } \\
\hline \multirow{3}{*}{ Estatística } & & $\Delta \%$ & & & Dívida & Dívida & Dívida & Pgto. \\
\hline & Sub-Amostra & Vendas & ROA & Caixa & Curto & Longo & Moeda & Dividendos \\
\hline & & & & & Prazo & Prazo & Est. & (dummy) \\
\hline \multirow{5}{*}{ Média } & Não Restritas & 0,084 & 0,083 & 0,105 & 0,121 & 0,186 & 0,177 & 0,812 \\
\hline & Restritas & 0,010 & 0,043 & 0,064 & 0,139 & 0,122 & 0,076 & 0,467 \\
\hline & Diferença & 0,073 & 0,040 & 0,040 & $-0,018$ & 0,064 & 0,101 & 0,344 \\
\hline & Teste $t$ & $6,33^{* * *}$ & $7,93^{* * *}$ & $8,32^{* * *}$ & $-2,98^{* * *}$ & $9,75^{* * *}$ & $14,44^{* * *}$ & $13,85^{* * *}$ \\
\hline & Total & 0,047 & 0,063 & 0,084 & 0,130 & 0,154 & 0,129 & 0,639 \\
\hline \multirow{4}{*}{ Mediana } & Não Restritas & 0,063 & 0,079 & 0,077 & 0,096 & 0,182 & 0,158 & 1,000 \\
\hline & Restritas & 0,017 & 0,049 & 0,023 & 0,094 & 0,070 & 0,025 & 0,000 \\
\hline & Teste Wilcoxon & $5,8^{* * *}$ & $7,6^{* * *}$ & $11,3^{* * *}$ & 0,164 & $11,8^{* * *}$ & $15,3^{* * *}$ & $191,7^{* * *}$ \\
\hline & Total & 0,041 & 0,067 & 0,046 & 0,095 & 0,137 & 0,091 & 1,000 \\
\hline \multirow{3}{*}{ Desvio-Padrão } & Não Restritas & 0,208 & 0,072 & 0,100 & 0,094 & 0,116 & 0,134 & 0,391 \\
\hline & Restritas & 0,238 & 0,119 & 0,089 & 0,135 & 0,138 & 0,109 & 0,499 \\
\hline & Total & 0,226 & 0,101 & 0,097 & 0,117 & 0,131 & 0,133 & 0,481 \\
\hline \multirow[t]{2}{*}{ \# Obs } & Não Restritas & 746 & 753 & 753 & 753 & 753 & 630 & 743 \\
\hline & Restritas & 744 & 753 & 753 & 753 & 753 & 580 & 751 \\
\hline
\end{tabular}

Notas: Esta tabela apresenta estatísticas descritivas de variáveis relacionadas à capacidade de crédito e ao comportamento esperado de firmas restritas ou não restritas por sub-amostra (Não Restritas, Restritas e Total) de acordo com os dois esquemas de classificação a priori (Painel A - Ativo Total e Painel B - Setor e Ativo Total). A sub-amostra Total compreende as firmas classificadas como não restritas ou restritas. Observações do período compreendido pelos anos de 1996 e 2009 são usadas para computar as estatísticas descritivas. No caso da média reporta-se também a diferença entre as médias dos dois grupos (Não Restritas e Restritas) e o Teste $t$ de igualdade de médias (paramétrico) associado. No caso da mediana reporta-se também o Teste de soma de postos de Wilcoxon de igualdade de distribuições (ou medianas) (não paramétrico). A variável $\Delta \%$ Vendas é definida como a variação percentual nas vendas, isto é, $[\operatorname{Vendas}(t)-V$ endas $(t-1)] / V$ endas $(t-1)$. ROA é definida como a razão entre o lucro antes dos juros e impostos e o ativo total. Caixa é definida como a razão entre o caixa e o ativo total. Dívida Curto Prazo é definida como a razão entre as dívidas de curto prazo e o ativo total. Dívida Longo Prazo é definida como a razão entre as dívidas de longo prazo e o ativo total. Dívida Moeda Estrangeira é definida como a razão entre a dívida em moeda estrangeira e o ativo total. Pgto. Dividendos (dummy) é uma variável dummy que assume o valor 1 nos anos em que a firma pagou dividendos e 0 caso contrário. No caso da variável qualitativa Pgto. Dividendos (dummy) o "Teste $t$ " é o Teste $Z$ de igualdade de proporções e o "Teste Wilcoxon" é a medida de associação $\chi 2$ de Pearson. Todas as variáveis, exceto a dummy, foram winsorizadas em $1 \%$ (ambas as caudas). ${ }^{* * *}$ denota significância estatística ao nível de $1 \%$. 
Por fim, são apresentadas na Tabela 4 as correlações de Pearson entre as variáveis incluídas no modelo estimado. Entre as firmas classificadas como não restritas, há uma correlação positiva entre o investimento e as oportunidades de investimento, corroborando expectativas a priori. Ainda com relação a esse grupo de firmas, cabe destacar as correlações positivas entre o investimento e os fluxos de caixa e entre as oportunidades de investimento e os fluxos de caixa. Entre as firmas classificadas como restritas, não há uma correlação estatisticamente significante entre o investimento e as oportunidades de investimento, ao contrário do esperado, mas há uma correlação positiva entre o investimento e os fluxos de caixa. Ainda com relação a esse grupo, cabe destacar a correlação negativa entre as oportunidades de investimento e os fluxos de caixa. Para concluir, apesar de haver algumas correlações moderadas entre as variáveis incluídas no modelo, acredita-se que problemas de multicolinearidade são de menor ordem.

Tabela 4: Matriz de correlações das variáveis incluídas no modelo (1)

\begin{tabular}{|c|c|c|c|c|c|c|c|}
\hline \multicolumn{2}{|c|}{ Classificação $\longrightarrow$} & \multicolumn{3}{|c|}{ Ativo Total } & \multicolumn{3}{|c|}{ Setor e Ativo Total } \\
\hline Variável & Sub-Amostra & Inv & $\mathrm{Q}(\mathrm{t}-1)$ & FC & Inv & $\mathrm{Q}(\mathrm{t}-1)$ & FC \\
\hline \multirow[t]{2}{*}{$\mathrm{Q}(\mathrm{t}-1)$} & Não Restritas & $0,340^{* * *}$ & & & $0,361^{* * *}$ & & \\
\hline & Restritas & $-0,046$ & & & $-0,034$ & & \\
\hline \multirow[t]{2}{*}{ FC } & Não Restritas & $0,294^{* * *}$ & $0,539^{* * *}$ & & $0,354^{* * *}$ & $0,367^{* * *}$ & \\
\hline & Restritas & $0,373^{* * *}$ & $-0,245^{* * *}$ & & $0,350^{* * *}$ & $-0,214^{* * *}$ & \\
\hline \multirow[t]{2}{*}{ Tang } & Não Restritas & 0,050 & 0,075 & $0,125^{* * *}$ & 0,045 & $0,104^{* * *}$ & $0,100^{* * *}$ \\
\hline & Restritas & 0,059 & $-0,051$ & $0,246^{* * *}$ & 0,057 & 0,008 & $0,235^{* * *}$ \\
\hline
\end{tabular}

Notas: Esta tabela apresenta as correlações de Pearson entre as variáveis incluídas no modelo (1) por sub-amostra (Não Restritas e Restritas) de acordo com os dois esquemas de classificação a priori (Ativo Total e Setor e Ativo Total). Observações do período compreendido pelos anos de 1996 e 2009 são usadas para computar as correlações. Inv é o investimento em ativos fixos por unidade de estoque de capital; $Q(t-1)$ é o $\mathrm{Q}$ de Tobin defasado em um período (ano); FC é o fluxo de caixa por unidade de estoque de capital; e Tang é a tangibilidade dos ativos. Para detalhes sobre a operacionalização dessas variáveis ver seção 2 . ${ }^{* * *}$ denota significância estatística ao nível de $1 \%$.

\subsection{Resultados Principais}

Concluída a análise preliminar das variáveis, passa-se agora a discutir os resultados das estimações do modelo (1), reportados na Tabela 5 , bem como os efeitos marginais da variável fluxos de caixa (ver equação (2)), reportados na Tabela 6. Inicia-se a análise pelos resultados obtidos sob a classificação Ativo Total. Para o grupo de firmas classificadas como não restritas financeiramente, a variável oportunidades de investimento ( $Q$ de Tobin) é a única no nível de firma capaz de explicar parte das variações no investimento corporativo. O coeficiente dessa variável é positivo, estatisticamente significante (ao nível de $10 \%$ ) e, dessa forma, consistente com o modelo neoclássico de investimentos. A variável fluxos de caixa e sua interação com a tangibilidade dos ativos apresentam coeficientes estatisticamente não diferentes de zero, resultando em um efeito marginal nulo da variável fluxos de caixa (Tabela 6), mesmo nos níveis mais elevados da variável tangibilidade. Esses resultados sugerem que a disponibilidade de fundos internos não é um impulsionador do investimento para o grupo de firmas classificadas como não restritas, confirmando assim as expectativas a priori.

Para o grupo de firmas classificadas como restritas, nenhuma das variáveis explicativas no nível de firma apresenta coeficientes estatisticamente significantes. Apesar da variável fluxos de caixa e sua interação com a tangibilidade dos ativos apresentarem coeficientes estatisticamente não diferentes de zero, o efeito marginal da variável fluxos de caixa (Tabela 6) é positivo e estatisticamente significante (exceto quando calculado no $5^{\circ}$ percentil da variável tangibilidade). Esses resultados sugerem que 0 
modelo do $Q$ de Tobin marginal é inapropriado para esse grupo de firmas e que variações positivas na disponibilidade interna de recursos tem um efeito positivo sobre a demanda por investimentos desse grupo (possivelmente por relaxar as restrições financeiras). No entanto, o teste de Wald não permite rejeitar a hipótese nula de que os efeitos marginais calculados no $25^{\circ}$ e $75^{\circ}$ percentis da variável tangibilidade são iguais. Logo, não há evidências conclusivas de que a sensibilidade do investimento aos fluxos de caixa seja função crescente da tangibilidade dos ativos (efeito multiplicador), como sugere o modelo de Almeida e Campello (2007).

Em suma, os resultados encontrados sob a classificação Ativo Total, embora consistentes com os modelos de investimento sob racionamento de crédito, não permitem eliminar a hipótese alternativa de que a sensibilidade do investimento aos fluxos de caixa decorra apenas do fato de os fluxos de caixa conterem informações sobre oportunidades de investimentos não capturadas corretamente pela variável $Q$ de Tobin.

Sob a classificação Setor e Ativo Total os resultados também sugerem que há diferenças de comportamento entre os grupos de firmas no que tange a decisão de investimento, mas de forma consistente com o modelo de Almeida e Campello (2007). Para o grupo de firmas classificadas como não restritas financeiramente, a variável oportunidades de investimento apresenta coeficiente positivo, estatisticamente significante (ao nível de 1\%) e, dessa forma, consistente com o modelo neoclássico de investimentos. Apesar da variável fluxos de caixa apresentar coeficiente positivo e estatisticamente significante (ao nível de 10\%) na regressão, o efeito marginal dos fluxos de caixa (Tabela 6) é somente estatisticamente significante (ao nível de 10\%) nos níveis mais baixos da variável tangibilidade. Esses resultados sugerem que, em geral, as firmas classificadas como não restritas comportam-se exatamente como prevê o modelo neoclássico: a demanda por investimentos é sensível somente às oportunidades de investimento da firma.

Para o grupo de firmas classificadas como restritas financeiramente, as oportunidades de investimento (medidas pelo $Q$ de Tobin) não parecem afetar as decisões de investimento, sugerindo que o modelo do $Q$ de Tobin marginal é inapropriado nesse contexto. A variável fluxos de caixa também apresenta coeficiente estatisticamente não diferente de zero, mas a sua interação com a variável tangibilidade apresenta coeficiente positivo e estatisticamente significante (ao nível de $1 \%$ ), indicando a presença do efeito multiplicador de crédito entre as firmas classificadas como restritas financeiramente. O efeito marginal da variável fluxos de caixa (Tabela 6) é positivo, estatisticamente significante (exceto quando calculado no $5^{\circ}$ percentil da variável tangibilidade) e crescente na tangibilidade dos ativos, visto que o teste de Wald permite rejeitar a hipótese nula de que os efeitos marginais calculados no $25^{\circ}$ e $75^{\circ}$ percentis da variável tangibilidade são iguais. Esses resultados sugerem que as firmas classificadas como restritas comportam-se de maneira consistente com o modelo de Almeida e Campello (2007): a demanda por investimentos é sensível à disponibilidade de recursos internos e essa sensibilidade, além de positiva, é crescente na tangibilidade dos ativos.

Ainda com relação ao grupo de firmas classificadas como restritas, a variável tangibilidade apresenta coeficiente negativo e estatisticamente significante (ao nível de $10 \%$ ), indicando que essa variável pode ter um impacto direto negativo sobre o investimento corporativo, contrariando as expectativas a priori. No entanto, o efeito marginal da variável tangibilidade (ver equação (3)) é estatisticamente não diferente de zero quando calculado na média e mediana da variável fluxos de caixa. ${ }^{17}$ Esses resultados sugerem que, em geral, a tangibilidade têm apenas efeitos indiretos sobre o investimento corporativo ao impactar na sensibilidade do investimento aos fluxos de caixa, embora tenha um efeito direto negativo entre firmas com fluxos de caixa próximos de zero ou negativos.

Em suma, os resultados encontrados sob a classificação Setor e Ativo Total corroboram aqueles encontrados por Almeida e Campello (2007) na realidade norte-americana e diferem substancialmente daqueles evidenciados por Terra (2003), Hamburger (2004), Esteves Filho e Ness Jr. (2005) e Aldrighi e Bisinha (2010) na realidade brasileira. Além disso, ao se mostrarem consistentes com os modelos de

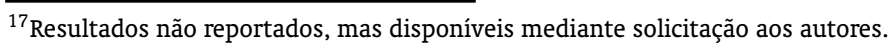


investimento sob racionamento de crédito e, especialmente, com o efeito multiplicador de crédito no nível de firma delineado por Almeida e Campello (2007), esses resultados enfraquecem a hipótese alternativa de que a sensibilidade do investimento aos fluxos de caixa decorra apenas do fato de os fluxos de caixa conterem informações sobre oportunidades de investimentos não capturadas corretamente pela variável $Q$ de Tobin. Por fim, os resultados encontrados, aliados ao argumento utilizado para justificar a adoção desse critério de classificação, sugerem que a separação das firmas em restritas e não restritas relativamente ao setor constitui estratégia adequada de classificação.

Tabela 5: Resultados das estimações por efeitos fixos do modelo de investimento (1)

\begin{tabular}{|c|c|c|c|c|}
\hline \multirow{2}{*}{$\begin{array}{l}\text { Classificação } \longrightarrow \\
\text { Sub-Amostra } \longrightarrow\end{array}$} & \multicolumn{2}{|c|}{ Ativo Total } & \multicolumn{2}{|c|}{ Setor e Ativo Total } \\
\hline & Não Restritas & Restritas & Não Restritas & Restritas \\
\hline \multirow[t]{2}{*}{ Constante } & 0.186 & $0.239^{* * *}$ & 0.168 & $0.266^{* * *}$ \\
\hline & {$[1.60]$} & [3.83] & {$[1.43]$} & [4.15] \\
\hline \multirow[t]{2}{*}{$\mathrm{Q}(\mathrm{t}-1)$} & $0.0683^{*}$ & -0.00786 & $0.0940^{* * *}$ & -0.000681 \\
\hline & {$[1.94]$} & {$[-0.75]$} & [2.82] & {$[-0.06]$} \\
\hline \multirow[t]{2}{*}{$\mathrm{FC}(\mathrm{t})$} & -0.0221 & 0.0213 & $0.137^{*}$ & -0.00622 \\
\hline & {$[-0.14]$} & {$[0.47]$} & {$[1.70]$} & {$[-0.16]$} \\
\hline \multirow[t]{2}{*}{ Tang $(\mathrm{t})$} & -0.185 & -0.149 & -0.162 & $-0.199^{*}$ \\
\hline & {$[-0.89]$} & {$[-1.40]$} & {$[-0.75]$} & {$[-1.90]$} \\
\hline \multirow[t]{2}{*}{ FC $x$ Tang $(t)$} & 0.0205 & 0.161 & -0.150 & $0.270^{* * *}$ \\
\hline & {$[0.06]$} & {$[1.47]$} & {$[-0.73]$} & {$[2.82]$} \\
\hline Dummies de Ano & Sim & Sim & $\operatorname{Sim}$ & Sim \\
\hline R-quad (within) & $11,20 \%$ & $12,60 \%$ & $11,30 \%$ & $9,97 \%$ \\
\hline R-quad (within) ajustado & $9,22 \%$ & $10,70 \%$ & $9,24 \%$ & $7,89 \%$ \\
\hline R-quad (between) & $11,80 \%$ & $24,60 \%$ & $22,20 \%$ & $21,40 \%$ \\
\hline R-quad (overall) & $12,30 \%$ & $16,60 \%$ & $17,60 \%$ & $14,20 \%$ \\
\hline $\mathrm{F}$ & 3,19 & 3,65 & 4,13 & 4,04 \\
\hline $\mathrm{N}$ & 767 & 767 & 753 & 753 \\
\hline Firmas & 118 & 131 & 123 & 172 \\
\hline
\end{tabular}

Notas: Esta tabela apresenta os resultados das estimações por efeitos fixos do modelo (1). Observações do período compreendido pelos anos de 1996 e 2009 são usadas para estimar o modelo. A variável dependente é o investimento em ativos fixos por unidade de estoque de capital (Inv). As variáveis explicativas são: o $Q$ de Tobin defasado em um período $(Q(t-1))$; o fluxo de caixa por unidade de estoque de capital (FC); a tangibilidade dos ativos (Tang); e a interação entre o fluxo de caixa e a tangibilidade dos ativos (FC x Tang). Para detalhes sobre a operacionalização dessas variáveis ver seção 2 . Estatísticas t entre colchetes. ${ }^{* * *},{ }^{* *} \mathrm{e}^{*}$ denotam significância estatística aos níveis de 1,5 e $10 \%$, respectivamente.

Para demonstrar a significância econômica dos resultados reportados, calculou-se o impacto de um choque exógeno de um desvio-padrão na variável fluxos de caixa sobre a demanda por investimentos das firmas classificadas como restritas (classificação Setor e Ativo Total). Para uma firma com tangibilidade igual ao $25^{\circ}$ percentil dessa variável o impacto é de $0,491 \times 0,097=0,048$, ou aproximadamente $27 \%$ (39\%) do valor médio (mediano) da variável investimentos nesse grupo. Já para uma firma com tangibilidade igual ao $75^{\circ}$ percentil dessa variável o impacto é de $0,491 \times 0,136=0,067$, ou aproximadamente $38 \%(55 \%)$ do valor médio (mediano) da variável investimentos. Portanto, o efeito da disponibilidade interna de recursos sobre a demanda por investimentos das firmas classificadas como restritas, além de estatisticamente significante, é economicamente relevante.

Apesar de material, esse efeito é substancialmente inferior àquele reportado por Almeida e Campello (2007, p. 1449) para a realidade norte-americana. No modelo apresentado pelos referidos autores, a fração recuperável dos novos investimentos, isto é, a fração que poderia ser dada como garantia 
Tabela 6: Efeitos marginais da variável fluxos de caixa calculados em diversos pontos da distribuição da variável tangibilidade

\begin{tabular}{|c|c|c|c|c|c|c|c|c|c|}
\hline Classif. & Sub-Amostra & & & Tangi & lidade (Perc & atis) & & & Wald \\
\hline \multirow{5}{*}{ Ativo Total } & \multirow{3}{*}{ Não Restritas } & 5 & 10 & 25 & 50 & 75 & 90 & 95 & $\mathrm{p} 25=\mathrm{p} 75$ \\
\hline & & -0.0161 & -0.0154 & -0.0139 & -0.0125 & -0.0116 & -0.0106 & -0.00975 & 0,00 \\
\hline & & {$[-0.22]$} & {$[-0.22]$} & {$[-0.21]$} & {$[-0.18]$} & {$[-0.15]$} & {$[-0.12]$} & {$[-0.10]$} & 0,9549 \\
\hline & \multirow{2}{*}{ Restritas } & 0.0490 & $0.0600^{* *}$ & $0.0832^{* * * *}$ & $0.0967^{* * *}$ & $0.106^{* * * *}$ & $0.118^{* * * *}$ & $0.124^{* * * *}$ & 2,17 \\
\hline & & {$[1.61]$} & {$[2.30]$} & [3.62] & [3.74] & {$[3.61]$} & {$[3.36]$} & [3.24] & 0,1409 \\
\hline \multirow{4}{*}{ Setor e Ativo Total } & \multirow{2}{*}{ Não Restritas } & $0.0939^{*}$ & $0.0869^{*}$ & 0.0755 & 0.0649 & 0.0574 & 0.0497 & 0.0436 & 0,53 \\
\hline & & {$[1.93]$} & {$[1.78]$} & {$[1.43]$} & {$[1.08]$} & {$[0.86]$} & {$[0.67]$} & {$[0.54]$} & 0,4682 \\
\hline & \multirow{2}{*}{ Restritas } & 0.0305 & $0.0633^{* * *}$ & $0.0970^{* * * *}$ & $0.118^{* * * *}$ & $0.136^{* * * *}$ & $0.152^{* * * *}$ & $0.161^{* * * *}$ & 7,97 \\
\hline & & {$[1.07]$} & [2.83] & {$[4.52]$} & {$[4.91]$} & {$[4.91]$} & {$[4.79]$} & {$[4.72]$} & 0,0047 \\
\hline
\end{tabular}

Notas: Esta tabela apresenta os efeitos marginais da variável fluxos de caixa, calculados de acordo com a equação (2) do texto e com base nos coeficientes apresentados na Tabela 5, em diversos valores da distribuição da variável tangibilidade dos ativos. Os efeitos marginais são calculados separadamente para os grupos de firmas não restritas e restritas de acordo com os dois esquemas de classificação a priori (Ativo Total e Setor e Ativo Total). Estatísticas $t$ entre colchetes. O teste de Wald, reportado na última coluna, testa a hipótese de igualdade entre o efeito marginal calculado no $25^{\circ}$ e $75^{\circ}$ percentil da distribuição da variável tangibilidade. Em relação a esse teste a primeira linha refere-se ao valor do teste e a segunda linha ao seu $p$-value. ${ }^{* * *},{ }^{* *} \mathrm{e}^{*}$ denotam significância estatística aos níveis de 1, 5 e $10 \%$, respectivamente.

em um contrato de empréstimo, é uma função de sua tangibilidade bem como de outros fatores, tais como o ambiente legal que condiciona as relações entre tomadores de recursos e credores. Apesar das firmas brasileiras e norte-americanas se assemelharem em termos do aspecto tangibilidade dos ativos, as diferenças institucionais entre os dois países são marcantes. Como destacado na introdução, diversos são os fatores que levam a crer que a fração recuperável de um determinado ativo no Brasil é inferior àquela observada no mercado norte-americano. Logo, se o efeito multiplicador de crédito sugerido por Almeida e Campello (2007) realmente existe, é razoável supor que a sensibilidade do investimento aos fluxos de caixa das firmas brasileiras seja de fato inferior àquela observada para as firmas norteamericanas. Os resultados aqui reportados são consistentes com essa visão e, portanto, constituem mais uma evidência (original) de que há um efeito multiplicador em ação no mercado de crédito.

\subsection{Testes de Robustez}

Na literatura, a principal crítica aos modelos que incorporam a variável fluxos de caixa como forma de medir o efeito de restrições ao crédito sobre o investimento corporativo é a de que essa variável pode ser uma medida das oportunidades de investimento não capturadas pela variável $Q$ de Tobin, quando esta última é medida com erro. Para contornar esse problema e verificar a robustez dos resultados estimou-se o seguinte modelo do acelerador de vendas, cuja versão reduzida (sem as variáveis fluxos de caixa e tangibilidade) é comumente empregada na literatura empírica de investimentos: ${ }^{18}$

$$
\begin{gathered}
\text { Inv }_{i, t}=\gamma_{i}+\pi_{1} \Delta \% \text { Vendas }_{i, t-1}+\pi_{2} F C_{i, t}+\pi_{3} \text { Tang }_{i, t}+ \\
\pi_{4}\left(F C_{i, t} \times \text { Tang }_{i, t}\right)+\tau_{t}+\epsilon_{i, t}
\end{gathered}
$$

Para fins de comparação somente, o modelo do acelerador também foi estimado incluindo a variável $Q$ de Tobin entre as explicativas. Os resultados dessas estimações, reportados na Tabela 7, corroboram aqueles anteriormente apresentados e discutidos e sugerem que os mesmos não são frutos de viéses decorrentes de erros de mensuração na variável oportunidades de investimento.

A estrutura dos dados empregados nas análises é a de um painel não balanceado. Assim, o conjunto de firmas que compõe a amostra varia ao longo dos anos. Poderia-se argumentar que a inclu-

$\overline{{ }^{18} \text { Ver, por exemplo, Kammler e Alves (2005). }}$ 
Tabela 7: Resultados das estimações por efeitos fixos do modelo do acelerador

\begin{tabular}{|c|c|c|c|c|c|c|c|c|}
\hline \multirow{3}{*}{$\begin{array}{l}\text { Classificação } \longrightarrow \\
\text { Sub-Amostra } \longrightarrow \\
\text { Constante }\end{array}$} & \multicolumn{4}{|c|}{ Ativo Total } & \multicolumn{4}{|c|}{ Setor e Ativo Total } \\
\hline & \multicolumn{2}{|c|}{ Não Restritas } & \multicolumn{2}{|c|}{ Restritas } & \multicolumn{2}{|c|}{ Não Restritas } & \multicolumn{2}{|c|}{ Restritas } \\
\hline & 0.166 & 0.111 & $0.248^{* * *}$ & $0.254^{* * * *}$ & $0.288^{* * *}$ & $0.200^{*}$ & $0.264^{* * * *}$ & $0.267^{* * *}$ \\
\hline & [1.65] & {$[1.02]$} & {$[3.65]$} & {$[3.73]$} & {$[2.69]$} & {$[1.82]$} & {$[3.72]$} & {$[3.74]$} \\
\hline \multirow[t]{2}{*}{$\triangle \%$ Vendas $(\mathrm{t}-1)$} & 0.0170 & 0.00537 & $0.0478^{* * *}$ & $0.0486^{* * *}$ & -0.0167 & -0.0338 & $0.0571^{* *}$ & $0.0581^{* *}$ \\
\hline & {$[0.50]$} & {$[0.16]$} & {$[2.65]$} & {$[2.76]$} & {$[-0.54]$} & {$[-1.03]$} & {$[2.44]$} & {$[2.53]$} \\
\hline \multirow[t]{2}{*}{ Q de Tobin (t-1) } & & $0.0676^{*}$ & & -0.00982 & & $0.103^{* * *}$ & & -0.00717 \\
\hline & & {$[1.88]$} & & {$[-0.87]$} & & {$[2.75]$} & & {$[-0.64]$} \\
\hline \multirow[t]{2}{*}{ Fluxo de Caixa (t) } & 0.00493 & 0.0276 & 0.00583 & 0.00945 & 0.0397 & -0.00973 & -0.0174 & -0.0159 \\
\hline & {$[0.03]$} & {$[0.18]$} & {$[0.12]$} & {$[0.19]$} & {$[0.46]$} & {$[-0.12]$} & {$[-0.43]$} & {$[-0.38]$} \\
\hline \multirow[t]{2}{*}{ Tangibilidade (t) } & -0.0673 & -0.0489 & -0.171 & -0.172 & -0.238 & -0.229 & $-0.211^{*}$ & $-0.207^{*}$ \\
\hline & {$[-0.35]$} & {$[-0.25]$} & {$[-1.52]$} & {$[-1.52]$} & {$[-1.13]$} & {$[-1.11]$} & {$[-1.83]$} & {$[-1.79]$} \\
\hline \multirow[t]{2}{*}{ Fluxo Caixa $\mathrm{x}$ Tangibilidade $(\mathrm{t})$} & 0.0184 & -0.115 & 0.171 & 0.167 & 0.0626 & 0.0982 & $0.280^{* * * *}$ & $0.281^{* * *}$ \\
\hline & {$[0.06]$} & {$[-0.32]$} & [1.38] & [1.33] & {$[0.30]$} & {$[0.48]$} & {$[2.67]$} & {$[2.63]$} \\
\hline Dummies de Ano & Sim & Sim & Sim & Sim & Sim & Sim & Sim & Sim \\
\hline R-quad (within) & $10,30 \%$ & $11,90 \%$ & $13,30 \%$ & $13,40 \%$ & $9,53 \%$ & $12,40 \%$ & $11,20 \%$ & $11,30 \%$ \\
\hline R-quad (within) ajustado & $8,14 \%$ & $9,63 \%$ & $11,20 \%$ & $11,20 \%$ & $7,33 \%$ & $10,10 \%$ & $8,98 \%$ & $8,92 \%$ \\
\hline R-quad (between) & $15,60 \%$ & $11,80 \%$ & $26,50 \%$ & $25,80 \%$ & $22,90 \%$ & $11,30 \%$ & $25,50 \%$ & $24,90 \%$ \\
\hline R-quad (overall) & $9,34 \%$ & $11,90 \%$ & $18,40 \%$ & $18,20 \%$ & $11,30 \%$ & $16,10 \%$ & $16,10 \%$ & $15,90 \%$ \\
\hline $\mathrm{F}$ & 2,83 & 2,81 & 3,45 & 3,23 & 3,46 & 3,58 & 3,76 & 3,52 \\
\hline $\mathrm{N}$ & 729 & 729 & 718 & 718 & 717 & 717 & 690 & 690 \\
\hline Firmas & 117 & 117 & 131 & 131 & 121 & 121 & 166 & 166 \\
\hline
\end{tabular}

Notas: Esta tabela apresenta os resultados das estimações por efeitos fixos do modelo do acelerador (4). Observações do período compreendido pelos anos de 1996 e 2009 são usadas para estimar o modelo. A variável dependente é o investimento em ativos fixos por unidade de estoque de capital (Inv). As variáveis explicativas são: a variação percentual em vendas defasada em um período ( $\triangle \%$ Vendas ( $\mathrm{t}-1)$ ); o $\mathrm{Q}$ de Tobin defasado em um período (Q(t-1)) (presente somente em algumas das regressões estimadas); o fluxo de caixa por unidade de estoque de capital (FC); a tangibilidade dos ativos (Tang); e a interação entre o fluxo de caixa e a tangibilidade dos ativos (FC x Tang). Para detalhes sobre a operacionalização dessas variáveis ver seção 2 e Tabela 3. Estatísticas t entre colchetes. *** ${ }^{* *}$ e * denotam significância estatística aos níveis de 1, 5 e $10 \%$, respectivamente.

são/exclusão das firmas ao longo do tempo (seleção da amostra) não é aleatória e que pode estar correlacionada com fatores determinantes do investimento excluídos do modelo estimado. ${ }^{19}$ Se esse for o caso, os resultados poderiam estar contaminados por um viés de seleção (neste contexto, comumentemente denominado de viés de sobrevivência). Para verificar essa possibilidade, estimou-se novamente 0 modelo (1) incluindo entre as variáveis explicativas a variável de seleção defasada (um indicador da presença da firma na amostra no período $t-1)$, conforme sugere Wooldridge (2002, p. 581). Os resultados, não reportados por motivos de concisão, são qualitativamente semelhantes aos apresentados na Tabela 5 e o coeficiente da variável de seleção defasada não é estatisticamente diferente de zero em todas as regressões, sugerindo que não há um viés de sobrevivência contaminando os resultados.

Ainda nessa linha, poderia-se argumentar que os critérios usados para eliminar observações da amostra (baseados no estoque de capital, crescimento das vendas e $Q$ de Tobin) afetariam os resultados (por um viés de seleção). Para eliminar essa hipótese, repetiram-se as análises com a amostra sem as referidas exclusões e os resultados encontrados são qualitativamente semelhantes aos reportados anteriormente (com exclusões) na seção 3.2. Mais uma vez, por motivos de concisão, esses resultados não são apresentados, porém todos eles estão disponíveis sob requisação aos autores.

Como argumentado anteriormente, a sensibilidade do investimento aos fluxos de caixa dependeria da fração recuperável dos novos investimentos Almeida e Campello (2007). É bem provável que essa fração recuperável varie com as condições macroeconômicas e, portanto, seria prudente verificar se a sensibilidade do investimento aos fluxos de caixa varia com essas condições. Para tal, poderia-se estimar o modelo de investimento (1) em diversos sub-períodos caracterizados por condições macroeconômicas

\footnotetext{
${ }^{19}$ Agradecemos a um parecerista anônimo por levantar esta questão.
} 
distintas. ${ }^{20}$ Essa abordagem, no entanto, implica na redução substancial do número de observações (graus de liberdade). Para contornar esse problema, optou-se por estimar o modelo (1) aumentado pela inclusão de interações entre as dummies de sub-períodos e as variáveis fluxos de caixa e sua interação com a tangibilidade dos ativos. Ao longo dos anos da amostra, o país passou por diversas turbulências macroeconômicas, dentre as quais podem ser destacadas as seguintes: mudança do regime cambial em 1999, crise de 2002 e a crise financeira internacional de 2008-2009. Com base nisso, estimou-se o seguinte modelo:

$$
\begin{aligned}
\operatorname{Inv}_{i, t}= & \alpha_{i}+\beta_{1} Q_{i, t-1}+ \\
& \left(\beta_{2}+\beta_{3} \times d_{99-02}+\beta_{4} \times d_{03-07}+\beta_{5} \times d_{08-09}\right) F C_{i, t}+\beta_{6} \text { Tang }_{i, t}+ \\
& \left(\beta_{7}+\beta_{8} \times d_{99-02}+\beta_{9} \times d_{03-07}+\beta_{10} \times d_{08-09}\right)\left(F C_{i, t} \times \text { Tang }_{i, t}\right)+ \\
& \mu_{t}+\varepsilon_{i, t}
\end{aligned}
$$

em que: $d_{99-02}, d_{03-07}$ e $d_{08-09}$ são variáveis indicadoras dos sub-períodos compreendidos pelos anos de 1999 e 2002, 2003 e 2007 e 2008 e 2009, respectivamente. Assim, por exemplo, a variável $d_{99-02}$ assume o valor 1 se o ano $\in\{1999,2000,2001,2002\}$ e 0 caso contrário. Uma vez estimado o modelo (5), a sensibilidade do investimento aos fluxos de caixa pode ser assim obtida:

$$
\begin{aligned}
\frac{\partial \operatorname{Inv} v}{\partial F C}= & \left(\beta_{2}+\beta_{3} \times d_{99-02}+\beta_{4} \times d_{03-07}+\beta_{5} \times d_{08-09}\right)+ \\
& \left(\beta_{7}+\beta_{8} \times d_{99-02}+\beta_{9} \times d_{03-07}+\beta_{10} \times d_{08-09}\right) \times \text { Tang }
\end{aligned}
$$

A expectativa é de que a sensibilidade do investimento aos fluxos de caixa das firmas restritas seja maior em períodos de maior prosperidade, em que a fração recuperável dos ativos tende a ser relativamente maior. Este é o caso do sub-período compreendido pelos anos de 2003 e 2007, período em que o Brasil experimentou taxas de crescimento relativamente altas. Na Tabela 8 são apresentados os efeitos marginais da variável fluxos de caixa por sub-período e para diversos valores da distribuição da variável tangibilidade, calculados por meio de (6) com base nos coeficientes das regressões do modelo (5).

Sob a classificação Ativo Total (Painel A), as firmas classificadas como não restritas apresentaram sensibilidade do investimento aos fluxos de caixa positiva e estatisticamente significante nos sub-períodos 1999-2002 e 2003-2007 para valores elevados da distribuição da variável tangibilidade, contrariando expectativas a priori. Além disso, no sub-período 1999-2002 há indícios de que a referida sensibilidade aumenta com a tangibilidade dos ativos (ver teste de Wald), algo somente esperado para firmas restritas financeiramente. Com relação às firmas classificadas como restritas, a sensibilidade do investimento aos fluxos de caixa é positiva e estatisticamente significante em todos os sub-períodos, para a maior parte dos valores da distribuição da variável tangibilidade. Apesar de a sensibilidade crescer com a tangibilidade em todos os sub-períodos, o teste de Wald não permite afirmar que o crescimento é estatisticamente significativo, rejeitando a hipótese do multiplicador de crédito no nível de firma proposto por Almeida e Campello (2007). A expectativa de que a sensibilidade do investimento aos fluxos de caixa das firmas restritas seja maior em períodos de maior prosperidade também não encontra respaldo nesses resultados.

Sob a classificação Setor e Ativo Total (Painel B), as firmas classificadas como não restritas também apresentaram sensibilidade do investimento aos fluxos de caixa positiva e estatisticamente significante nos sub-períodos 1999-2002 e 2003-2007, contrariando expectativas a priori. A sensibilidade do investimento aos fluxos de caixa decresce com a tangibilidade, embora esse decréscimo não seja estatisticamente significante (ver teste de Wald), sugerindo que não há um efeito multiplicador de crédito em

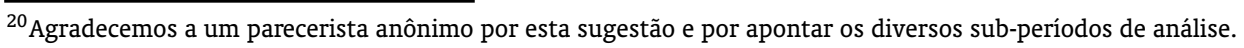


ação nesse grupo de firmas. Com relação às firmas classificadas como restritas, a sensibilidade do investimento aos fluxos de caixa é positiva e estatisticamente significante em todos os sub-períodos, para a maior parte dos valores da distribuição da variável tangibilidade. A sensibilidade do investimento aos fluxos de caixa cresce com a tangibilidade dos ativos em todos os sub-períodos, mas o crescimento é estatisticamente significativo somente no sub-período 2003-2007 (ver teste de Wald). Esses resultados sugerem, portanto, a presença de um efeito multiplicador de crédito nesse grupo de firmas no sub-período 2003-2007. Finalmente, observa-se que a sensibilidade do investimento aos fluxos de caixa das firmas classificadas como restritas é relativamente maior nos sub-períodos 1996-1998 e 2003-2007, corroborando parcialmente as expectativas.

Tabela 8: Efeitos marginais da variável fluxos de caixa por sub-período

\begin{tabular}{|c|c|c|c|c|c|c|c|c|c|}
\hline \multicolumn{10}{|c|}{ Painel A: Classificação Ativo Total } \\
\hline \multirow{2}{*}{ Sub-Amostra } & \multirow{2}{*}{ Sub-Período } & \multicolumn{7}{|c|}{ Tangibilidade (Percentis) } & \multirow{2}{*}{$\begin{array}{l}\text { Wald } \\
\text { p25=p75 }\end{array}$} \\
\hline & & 5 & 10 & 25 & 50 & 75 & 90 & 95 & \\
\hline \multirow{8}{*}{ 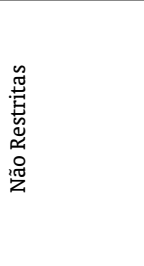 } & \multirow{2}{*}{$1996-1998$} & $-0,002$ & 0,005 & 0,021 & 0,036 & 0,045 & 0,057 & 0,065 & 0,16 \\
\hline & & {$[-0,02]$} & {$[0,06]$} & {$[0,28]$} & {$[0,45]$} & {$[0,50]$} & {$[0,51]$} & {$[0,51]$} & 0,69 \\
\hline & \multirow{2}{*}{$1999-2002$} & $-0,067$ & $-0,041$ & 0,014 & 0,068 & $0,103^{* *}$ & $0,142^{* * *}$ & $0,172^{* * *}$ & 3,74 \\
\hline & & {$[-0,58]$} & {$[-0,40]$} & {$[0,19]$} & {$[1,19]$} & {$[2,22]$} & {$[3,41]$} & {$[3,88]$} & 0,06 \\
\hline & \multirow{2}{*}{$2003-2007$} & 0,097 & 0,100 & 0,106 & $0,113^{*}$ & $0,117^{*}$ & 0,121 & 0,125 & 0,05 \\
\hline & & {$[0,97]$} & {$[1,11]$} & {$[1,46]$} & {$[1,72]$} & {$[1,73]$} & {$[1,60]$} & {$[1,46]$} & 0,83 \\
\hline & \multirow{2}{*}{$2008-2009$} & $-0,239^{* * *}$ & $-0,232^{* * *}$ & $-0,217^{* *}$ & $-0,202^{* *}$ & $-0,193^{*}$ & $-0,182$ & $-0,174$ & 0,28 \\
\hline & & {$[-2,62]$} & {$[-2,66]$} & {$[-2,55]$} & {$[-2,20]$} & {$[-1,92]$} & {$[-1,62]$} & {$[-1,41]$} & 0,60 \\
\hline \multirow{8}{*}{ 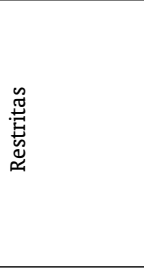 } & \multirow{2}{*}{$1996-1998$} & $0,120^{*}$ & $0,121^{\text {** }}$ & $0,123^{* * *}$ & $0,124^{* * *}$ & $0,125^{* * *}$ & $0,126^{* * *}$ & $0,126^{* *}$ & 0,01 \\
\hline & & {$[1,78]$} & {$[2,09]$} & {$[2,88]$} & {$[3,12]$} & {$[3,02]$} & {$[2,69]$} & {$[2,50]$} & 0,94 \\
\hline & \multirow{2}{*}{$1999-2002$} & 0,002 & 0,020 & $0,057^{*}$ & $0,078^{* *}$ & $0,093^{* *}$ & $0,112^{* *}$ & $0,121^{* *}$ & 1,68 \\
\hline & & {$[0,04]$} & {$[0,39]$} & {$[1,69]$} & {$[2,43]$} & {$[2,59]$} & {$[2,50]$} & {$[2,42]$} & 0,20 \\
\hline & \multirow{2}{*}{$2003-2007$} & 0,050 & 0,060 & $0,082^{* *}$ & $0,095^{* * *}$ & $0,105^{* * *}$ & $0,116^{* * *}$ & $0,122^{* * *}$ & 0,71 \\
\hline & & {$[0,76]$} & {$[1,11]$} & {$[2,32]$} & {$[3,11]$} & {$[3,31]$} & {$[3,09]$} & {$[2,91]$} & 0,40 \\
\hline & \multirow{2}{*}{$2008-2009$} & 0,057 & $0,069^{*}$ & $0,093^{* *}$ & $0,108^{* *}$ & $0,118^{* *}$ & $0,131^{* *}$ & $0,137^{* *}$ & 1,27 \\
\hline & & {$[1,37]$} & {$[1,86]$} & {$[2,52]$} & {$[2,53]$} & {$[2,44]$} & {$[2,30]$} & {$[2,24]$} & 0,26 \\
\hline \multicolumn{10}{|c|}{ Painel B: Classificação Setor e Ativo Total } \\
\hline \multirow{8}{*}{ 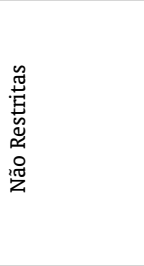 } & \multirow{2}{*}{$1996-1998$} & $-0,039$ & $-0,043$ & $-0,048$ & $-0,053$ & $-0,057$ & $-0,061$ & $-0,063$ & 0,25 \\
\hline & & {$[-0,92]$} & {$[-0,90]$} & {$[-0,85]$} & {$[-0,81]$} & {$[-0,79]$} & {$[-0,77]$} & {$[-0,75]$} & 0,62 \\
\hline & \multirow{2}{*}{$1999-2002$} & $0,177^{* *}$ & $0,166^{* *}$ & $0,150^{* * *}$ & $0,135^{* * *}$ & $0,124^{* * *}$ & $0,113^{* *}$ & $0,104^{* *}$ & 0,84 \\
\hline & & {$[2,31]$} & {$[2,45]$} & {$[2,66]$} & {$[2,75]$} & {$[2,64]$} & {$[2,36]$} & {$[2,06]$} & 0,36 \\
\hline & \multirow{2}{*}{$2003-2007$} & $0,255^{* * *}$ & $0,253^{* * *}$ & $0,249^{* * * *}$ & $0,245^{* * *}$ & $0,243^{* * *}$ & $0,240^{* * *}$ & $0,238^{* *}$ & 0,02 \\
\hline & & {$[3,01]$} & {$[3,49]$} & {$[4,11]$} & {$[3,95]$} & {$[3,44]$} & {$[2,87]$} & {$[2,49]$} & 0,90 \\
\hline & \multirow{2}{*}{$2008-2009$} & $-0,103$ & $-0,094$ & $-0,079$ & $-0,065$ & $-0,056$ & $-0,046$ & $-0,038$ & 0,41 \\
\hline & & {$[-1,01]$} & {$[-0,97]$} & {$[-0,86]$} & {$[-0,71]$} & {$[-0,58]$} & {$[-0,45]$} & {$[-0,35]$} & 0,52 \\
\hline \multirow{8}{*}{ 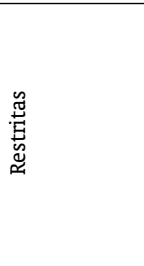 } & \multirow{2}{*}{$1996-1998$} & $0,178^{*}$ & $0,187^{* *}$ & $0,196^{* * *}$ & $0,201^{* * *}$ & $0,206^{* * *}$ & $0,210^{* * *}$ & $0,212^{* * *}$ & 0,08 \\
\hline & & {$[1,67]$} & {$[2,32]$} & {$[3,37]$} & {$[4,12]$} & {$[4,41]$} & {$[4,26]$} & {$[4,04]$} & 0,77 \\
\hline & \multirow{2}{*}{$1999-2002$} & 0,037 & 0,060 & $0,083^{* *}$ & $0,098^{* * *}$ & $0,110^{* * *}$ & $0,121^{* * *}$ & $0,127^{* * *}$ & 1,18 \\
\hline & & {$[0,64]$} & {$[1,39]$} & {$[2,46]$} & {$[2,87]$} & {$[2,88]$} & {$[2,74]$} & {$[2,65]$} & 0,28 \\
\hline & \multirow{2}{*}{$2003-2007$} & 0,003 & 0,046 & $0,090^{* * *}$ & $0,118^{* * *}$ & $0,141^{* * *}$ & $0,162^{* * *}$ & $0,173^{* * *}$ & 7,51 \\
\hline & & {$[0,07]$} & {$[1,40]$} & {$[3,50]$} & {$[4,61]$} & {$[4,96]$} & {$[4,96]$} & {$[4,89]$} & 0,01 \\
\hline & \multirow{2}{*}{$2008-2009$} & 0,021 & 0,053 & $0,085^{* *}$ & $0,106^{* *}$ & $0,123^{* *}$ & $0,139^{* *}$ & $0,147^{* *}$ & 2,47 \\
\hline & & {$[0,42]$} & {$[1,26]$} & {$[1,98]$} & {$[2,17]$} & {$[2,22]$} & {$[2,22]$} & {$[2,21]$} & 0,12 \\
\hline
\end{tabular}

Notas: Esta tabela apresenta os efeitos marginais da variável fluxos de caixa, calculados de acordo com a equação (6) do texto e com base nos coeficientes das regressões do modelo (5), em diversos valores da distribuição da variável tangibilidade dos ativos. Os efeitos marginais são calculados separadamente para os grupos de firmas não restritas e restritas de acordo com os dois esquemas de classificação a priori: Ativo Total (Painel A) e Setor e Ativo Total (Painel B). Estatísticas $t$ entre colchetes. O teste de Wald, reportado na última coluna, testa a hipótese de igualdade entre o efeito marginal calculado no $25^{\circ}$ e $75^{\circ}$ percentil da distribuição da variável tangibilidade. Em relação a esse teste a primeira linha refere-se ao valor do teste e a segunda linha ao seu p-value. ${ }^{* * *}$, ${ }^{* *} \mathrm{e}^{*}$ denotam significância estatística aos níveis de 1,5 e $10 \%$, respectivamente.

Por fim, a variável tangibilidade dos ativos foi definida como uma soma ponderada de quatro elementos patrimoniais, sendo os pesos determinados para a economia norte-americana. Para verificar 
se os resultados encontrados são fruto dessa ponderação, estimou-se novamente o modelo de investimento (1) substituindo a variável tangibilidade original por uma versão sem ponderação. Os resultados dessas estimações, não reportados por motivos de concisão, são qualitativamente semelhantes àqueles apresentados nas Tabelas 5 e 7 e, portanto, sugerem que os resultados não decorrem da ponderação utilizada na definição da variável tangibilidade.

\section{CONSIDERAÇÕES FINAIS}

O presente estudo teve como objetivo testar a relação entre restrições ao crédito e demanda por investimentos das firmas brasileiras utilizando a estratégia de identificação desenhada por Almeida e Campello (2007). Para alcançar tal objetivo, equações de investimento foram estimadas para grupos de firmas classificadas a priori como restritas e não restritas de acordo com dois esquemas de classificação: Ativo Total e Setor e Ativo Total.

Quando as firmas são classificadas a priori de acordo com o Ativo Total, os resultados sugerem diferenças de comportamento entre os grupos de firmas: o grupo de firmas classificadas como não restritas comporta-se de forma consistente com o modelo neoclássico de investimento, isto é, a demanda por investimentos é sensível somente às oportunidades de investimento ( $Q$ de Tobin), enquanto que o grupo de firmas classificadas como restritas comporta-se de maneira consistente com os modelos de investimento sob racionamento de crédito, isto é, a demanda por investimentos é sensível à disponibilidade de recursos internos (fluxos de caixa). No entanto, não há evidências de que a sensibilidade do investimento aos fluxos de caixa seja função crescente da tangibilidade dos ativos, como sugere o modelo de Almeida e Campello (2007).

Quando classificadas a priori de acordo com o Setor e Ativo Total, os resultados também sugerem que há diferenças de comportamento entre os grupos de firmas no que tange à decisão de investimento, mas de forma consistente com o modelo de Almeida e Campello (2007). As firmas classificadas como não restritas, em geral, comportam-se exatamente como prevê o modelo neoclássico: a demanda por investimentos é sensível somente às oportunidades de investimento. As firmas classificadas como restritas, embora não apresentem sensibilidade do investimento às oportunidades de investimento, comportam-se de maneira consistente com o modelo de Almeida e Campello (2007): a demanda por investimentos é sensível à disponibilidade de recursos internos e essa sensibilidade, além de positiva, é crescente na tangibilidade dos ativos.

Os resultados sob a classificação Setor e Ativo Total corroboram aqueles encontrados por Almeida e Campello (2007) na realidade norte-americana e diferem substancialmente daqueles evidenciados por Terra (2003), Hamburger (2004), Esteves Filho e Ness Jr. (2005) e Aldrighi e Bisinha (2010) na realidade brasileira. Quanto à evidência inédita acerca do efeito multiplicador de crédito na realidade brasileira cabem algumas ressalvas e comentários. Embora presente, o seu efeito econômico é relativamente pequeno quando comparado àquele observado na realidade norte-americana [ver Almeida e Campello (2007) e Tabela 6 no presente estudo]. Acredita-se que, em grande parte, esses resultados devem-se às diferenças institucionais existentes entre os dois países. A existência (intensidade) do efeito multiplicador de crédito requer, por exemplo, que os credores possam tomar posse facilmente das garantias previamente acordadas no contrato de dívida, o que nem sempre é o caso na realidade brasileira. Portanto, para aliviar os efeitos negativos das restrições financeiras sobre as firmas e sobre a alocação de recursos na economia é imprescindível que se desenvolvam os mecanismos institucionais que permitam que a intermediação financeira funcione de forma mais eficiente. Por fim, cabe mencionar que, na análise dos sub-períodos, há indícios da existência de um multiplicador de crédito no nível de firma somente no sub-período 2003-2007, período em que o Brasil apresentou taxas de crescimento relativamente altas e em que o valor colaterizável dos ativos era provavelmente superior. 


\section{BIBLIOGRAFIA}

Aldrighi, D. M. \& Bisinha, R. (2010). Restrição financeira em empresas com ações negociadas na Bovespa. Revista Brasileira de Economia, 64(1):25-47.

Almeida, H. \& Campello, M. (2007). Financial constraints, asset tangibility, and corporate investment. The Review of Financial Studies, 20(5):1429-1460.

Beck, T., Demirgüç-Kunt, A., Laeven, L., \& Maksimovic, V. (2006). The determinants of financing obstacles. Journal of International Money and Finance, 25(6):932-952.

Beck, T., Demirgüç-Kunt, A., \& Levine, R. (2003). Law, endowments, and finance. Journal of Financial Economics, 70(2):137-181.

Berger, P. G., Ofek, E., \& Swary, I. (1996). Investor valuation of the abandonment option. Journal of Financial Economics, 42(2):257-287.

Bond, S., Klemm, A., Newton-Smith, R., Syed, M., \& Vlieghe, G. (2004). The roles of expected profitability, Tobin's $Q$ and cash flow in econometric models of company investment. Working Paper 04/12, IFS Working Papers, Institute for Fiscal Studies (IFS).

Cleary, S. (1999). The relationship between firm investment and financial status. The Journal of Finance, 54(2):673-692.

Cleary, S. (2005). Corporate investment and financial slack: International evidence. International Journal of Managerial Finance, 1(3):140-163.

Cleary, S., Povel, P., \& Raith, M. (2007). The U-shaped investment curve: Theory and evidence. Journal of Financial and Quantitative Analysis, 42(1):1-39.

Costa, C. M. \& Paz, L. S. (2004). Are Brazilian Firms Savings Sensitive to Cash Windfalls? In Anais do XXXII Encontro Nacional de Economia. ANPEC-Associação Nacional dos Centros de Pósgraduação em Economia.

Cummins, J. G., Hassett, K. A., \& Oliner, S. D. (2006). Investment behavior, observable expectations, and internal funds. The American Economic Review, 96(3):796-810.

Dyck, A. \& Zingales, L. (2004). Private benefits of control: An international comparison. The Journal of Finance, 59(2):537-600.

Erickson, T. \& Whited, T. M. (2000). Measurement error and the relationship between investment and q. Journal of Political Economy, 108(5):1027-1057.

Esteves Filho, M. \& Ness Jr., W. L. (2005). Restrições financeiras aos investimentos fixos de empresas brasileiras listadas em bolsa de valores no período de 1995 a 2003. In Anais do V Encontro Brasileiro de Finanças. SBFin-Sociedade Brasileira de Finanças.

Fazzari, S. M. \& Athey, M. J. (1987). Asymmetric information, financing constraints, and investment. The Review of Economics and Statistics, 69(3):481-487.

Fazzari, S. M., Hubbard, R. G., \& Petersen, B. C. (1988). Financing constraints and corporate investment. Brookings Papers on Economic Activity, 1:141-195.

Gilchrist, S. \& Himmelberg, C. P. (1995). Evidence on the role of cash flow for investment. Journal of Monetary Economics, 36(3):541-572. 
Gomes, J. F. (2001). Financing investment. The American Economic Review, 91(5):1263-1285.

Greenwald, B., Stiglitz, J. E., \& Weiss, A. (1984). Informational imperfections in the capital market and macroeconomic fluctuations. The American Economic Review, 74(2):194-199.

Guariglia, A. \& Schiantarelli, F. (1998). Production smoothing, firms' heterogeneity, and financial constraints: evidence from a panel of UK firms. Oxford Economic Papers, 50(1):63-78.

Hamburger, R. R. (2004). O efeito da variação do fluxo de caixa nos investimentos corporativos no Brasil. In Anais do XXVIII Encontro da Associação Nacional de Pós-Graduação e Pesquisa em Administração. ANPAD-Associação Nacional de Pós-Graduação e Pesquisa em Administração.

Hubbard, R. G. (1998). Capital-market imperfections and investment. Journal of Economic Literature, 36(1):193-225.

Jaffee, D. M. \& Russell, T. (1976). Imperfect information, uncertainty, and credit rationing. The Quarterly Journal of Economics, 90(4):651-666.

Kammler, E. L. \& Alves, T. W. (2005). Análise da capacidade de explicação dos investimentos das empresas brasileiras de capital aberto através do modelo do acelerador. Revista Contabilidade \& Finanças, 16(39):81-92.

Kaplan, S. N. \& Zingales, L. (1997). Do investment-cash flow sensitivities provide useful measures of financing constraints? The Quarterly Journal of Economics, 112(1):169-215.

La Porta, R., Lopez-de Silanes, F., Shleifer, A., \& Vishny, R. W. (1998). Law and finance. Journal of Political Economy, 106(6):1113-1155.

Leal, R. P. C. \& Saito, R. (2003). Finanças corporativas no Brasil. RAE eletrônica, 2(2):1-15.

Levine, R. (1999). Law, finance, and economic growth. Journal of Financial Intermediation, 8(1):8-35.

Modigliani, F. \& Miller, M. H. (1958). The cost of capital, corporation finance and the theory of investment. The American Economic Review, 48(3):261-297.

Myers, S. C. \& Majluf, N. S. (1984). Corporate financing and investment decisions when firms have information that investors do not have. Journal of Financial Economics, 13(2):187-221.

Stein, J. C. (2003). Handbook of the Economics of Finance, chapter Agency, information and corporate investment, pages 109-163. Elsevier.

Stiglitz, J. E. \& Weiss, A. (1981). Credit rationing in markets with imperfect information. The American Economic Review, 71(3):393-410.

Terra, M. C. T. (2003). Credit constraints in Brazilian firms: evidence from panel data. Revista Brasileira de Economia, 57(2):443-464.

Whited, T. M. (1992). Debt, liquidity constraints, and corporate investment: Evidence from panel data. The Journal of Finance, 47(2):1425-1460.

Wooldridge, J. M. (2002). Econometric analysis of cross section and panel data. The MIT Press.

Zani, J. \& Procianoy, J. L. (2005). Restrição financeira e a política financeira da firma: A variação na estocagem de liquidez determinada pelo status financeiro e pela sua geração de caixa operacional. In Anais do V Encontro Brasileiro de Finanças. SBFin-Sociedade Brasileira de Finanças. 